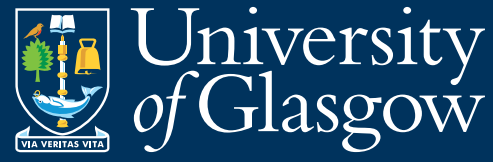

Adam Smith

Business School

WORKING

PAPER

SERIES

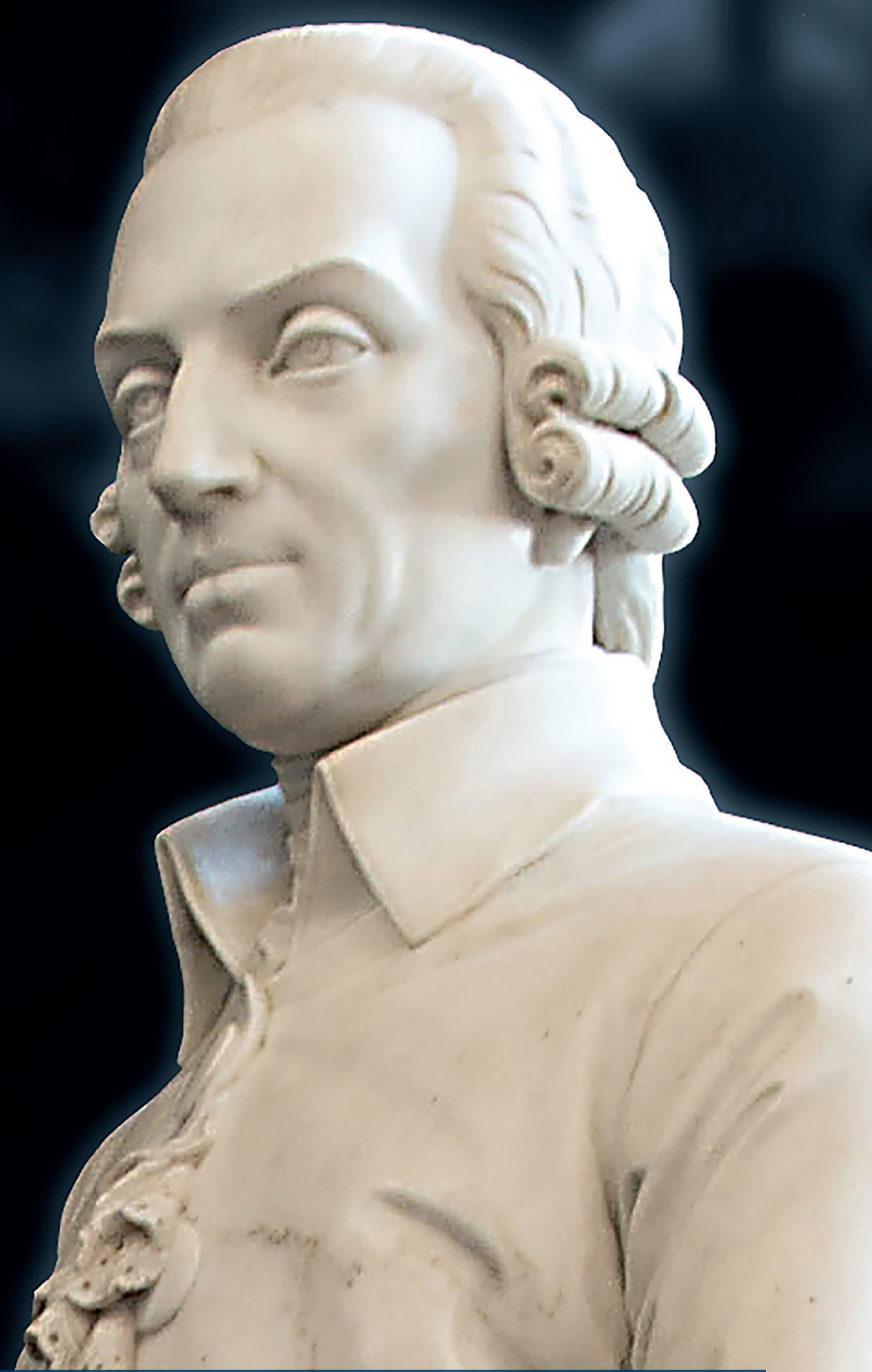

Do role models increase student hope and effort? Evidence from India

Prateek Chandra Bhan

Paper no. 2021-01

November 2020 


\title{
Do role models increase student hope and effort? Evidence from India*
}

\author{
Prateek Chandra Bhan ${ }^{\dagger}$
}

November 2020

\begin{abstract}
This paper offers experimental evidence on the significance of role-models on fostering hope, increasing effort and improving the academic performance of primary school students in India. Students from private schools were individually randomised to a treatment or a placebo group. Treated students watch a short film produced as a part of the experiment in Jaipur, Rajasthan - the study location. The placebo group students watch a television show for kids, 'Malgudi Days'. I find a 0.17 standard deviation (s.d.) increase in student hope and 0.25 s.d increase in their effort, immediately after the intervention. The one-off treatment leads to a 0.16 s.d. increase on standardised test scores in English, six-weeks after the intervention. Along with hope, I find significant improvements in students' self-efficacy or optimism and happiness. A cost-effectiveness analysis highlights role-models as a promising treatment intervention tool that can have an effect on student motivation and their learning outcomes.
\end{abstract}

Keywords: Role models, hope, effort, education, primary school, India.

JEL Codes: O12, I25, I21, J24

\footnotetext{
*I thank my supervisors Prof. Sayantan Ghosal, Dr. Theodore Koutmeridis and Prof. Michele Schweisfurth for their comments, support and encouragement. I would also thank Prof. Bruce Wydick and Dr. Patricio Dalton for their comments and advice throughout the study. I also thank the seminar participants at the University of San Francisco, University of Glasgow and ESA for their useful comments. I would like to thank the staff of Muskaan for their support in conducting the fieldwork. I am grateful to the team of Braille Cam, for their diligence and ingenuity in the production of the treatment video. I am also very thankful to the fieldwork team for the meticulous data collection, hard-work and research assistance. This study is funded by the College of Social Sciences (CoSS) Seed-corn funding, Adam Smith Business School (ASBS) field-work funds and the Behaviour, Structure and Interventions (BSI) Network. The analysis plan for the trial was registered in July 2019 before the data collection started. A revision was made in January 2020 before any analysis began.

†Department of Economics, Adam Smith Business School, University of Glasgow, Gilbert Scott Building, Glasgow, G12 8QQ, UK. E-mail: p.bhan.1@research.gla.ac.uk
} 


\section{Introduction}

"Hope is a good thing, may be the best of things, and no good thing ever dies"

- Andy Dufresne in The Shawshank Remption; Darabont and King (1994)

Hope, conceptualised as the combination of pathways and agentic thinking, has been an effective predictor of various academic activities (Snyder, 1994, and Snyder, et al. 1991), beyond any variations due to other psychological factors (Curry et al. 1997). However, any direct treatment that increases hope has eluded the literature in development economics. This paper, in an attempt to increase students' hope, provides evidence that not only does fostering hope improves other psychological facets like self-esteem and happiness, but also has complementary effects on effort and achievement.

Snyder (2002), argues that higher hope is consistently associated with higher self-efficacy or optimism, learned optimism, better psychological adjustment processes and outcomes in academics and athletics. For the scope of this research, I focus my attention on hope, optimism or self-efficacy, effort and academic performance in primary school children in India. Using these predictive capabilities of hope, I hypothesise that it is possible to increase hope, alike aspirations, through role-modelling interventions, and in doing so, also increase effort and academic performance.

Chong et al. (2012) along with many others in the following years, showed that exposure to relevant role models through multimedia channels can bring about behavioural changes. These changes can vary in terms of elevating individual aspirations (Riley, 2017; Dalton 2009; Bernard et al. 2014); influencing fertility decisions, household autonomy or the incidence of domestic violence (Chong and La Ferrara, 2009; Jensen and Oster, 2009; La Ferrara et al., 2012; McKelway 2019); and improving educational outcomes (Beaman et al., 2012 and Bettinger and Long, 2005), among many others.

Nguyen (2008) found a 0.17 sd increase in test scores from exposure to role mod- 
els that were relatable in terms of the socio-economic status in Madagascar. Riley (2017) found a similar effect in Uganda, where exposure to a motivational film 'Queen of Katwe' in local cinema increased student performance on Math test scores by $0.11-0.13$ sd.

Following recent role-modelling literature (Bernard et al, 2014; Dalton et al, 2020; and Garcia et al., 2019), I hired a production team in India to create a compilation of short films. These were edited to demonstrate the importance of hope and hard-work in goal attainability.

Carefully constructed instruments were used to capture information on psychological factors, effort and achievement. In addition to these instruments, I employed baseline survey questionnaires for collecting information on gender, age, religion and other covariates. 452 students were randomised at an individual level. Benefiting from the school infrastructure, students were treated at an individual level in their school's computer laboratories. Each student had access to a functional pair of monitor and ear-phones, with card-board pieces placed on each side and top of the screens.

I find that a 30-minute treatment movie increased student hope by $0.17 \mathrm{sd}$, optimism by $0.27 \mathrm{sd}$ and effort in a substitution class by $0.25 \mathrm{sd}$, immediately after the intervention. The effect on self-efficacy or optimism became stronger and persisted 6 weeks after. I find a 0.16 sd increase in English test scores 6 weeks after the treatment. This improvement in achievement is expected to be an outcome of higher hope, optimism and effort, along with many other unmeasured factors 1 . All of these effects are significant at 5 percent. While I do not find any treatment effects on student effort in attending an optional remedial class, the overall average treatment effect on remedial class attendance is $0.17 \mathrm{sd}$, significant at 1 percent. Furthermore, happiness for students started increasing modestly 1 week after the intervention by 0.2 sd with the

\footnotetext{
${ }^{1}$ Given the multiple overlapping channels through which the role-modelling intervention can affect behaviour and achievement, I do not attempt to parse out the effect of any of these other unmeasured channels. These can be aspirations, confidence or self-image (Ghosal et al., 2019), among others. Instead, I offer suggestive evidence on the role that hope, optimism and effort can play in improving academic performance measured on a standardised English test.
} 
effect persisting after 6 weeks.

The effect in hope is driven mainly by the lowest quantile of students as per their baseline hope scores. Upon further analysis, I find that while there were no heterogeneous treatment effects based on past performance; age at the time of the intervention held strong predictive power. Below median age students ${ }^{2}$ were significantly more optimistic ( $0.49 \mathrm{sd}$ at 1 percent) with the effect being stronger in the below median age female students.

I run a set of robustness checks on these findings. Firstly, I control for individual fixed effects and time-invariant confounding factors. Secondly, I winsorize my sample at 1 (and 99) and 5 (and 95) percent, to ensure that no outliers in the sample drive the results. I find that my findings are unchanged when I winsorize at 1 percent; with a minute loss of significance for psychological outcomes when I winsorize at 5 percent, which could be due to lost power. Thirdly, I follow Anderson (2008) and adjust the observed p-values to the slightly higher, yet significant, simulated p-values that are adjusted for family-wise error rates (FWER). Finally, I conducted respondent verification interviews with the respective school teachers, to complement my findings with qualitative information ${ }^{3}$.

Following Kremer et al. (2013), I conducted a cost-effectiveness analysis. The findings are encouraging as for each 100 USD spent, the intervention improved English test scores by $3.5 \mathrm{sd}$ and hope by $3.6 \mathrm{sd}$. These are comparable to Duflo et al. (2011) and Baird et al. $(2011,2016)$ in terms of the effect size, adding to the credibility of the potential policy implications. I find that a small push in hope is complemented by improvements in other psychological traits, with subsequent benefits in the form of heightened effort and improved learning outcomes.

The remainder of the paper is structured as follows. I start with a small documentation of the background literature and introduce the theory of change, accompa-

\footnotetext{
${ }^{2}$ The median age at baseline is 9 years.

${ }^{3}$ These interviews were conducted after the completion of the study without revealing the intent of the study or the nature of the different instruments.
} 
nied by a theoretical framework in Section 2. In Section 3, I explain the experimental set-up and the intervention. Details on the data collection methods and randomisation are summarised in Section 4. The empirical strategy, main results, along with an analyses for heterogeneous effects and robustness checks are presented in Section 5. Interpretation of these treatment effects and their cost-effectiveness is discussed in Section 6. Lastly, in Section 7, I conclude with the policy implications of this research.

\section{Background}

Addressing internal constraints and issues of student motivation have long eluded the impetus of education policy in many developing countries alike India ${ }^{4}$. Perhaps, making improvements in learning outcomes more desirable and attainable to students possesses a potential in this direction that is yet to be explored. Aided with empirical evidence, I argue that role-modelling interventions can be one of the many cheap and easily scalable ways forward.

A key issue with standard economic policy thinking has been the appreciation of people's preferences but the ignorance of people's motivation and other psychological factors that shape these preferences (Bertrand et al. 2005). Internal constraints deeply ingrain in children and strongly influence the feelings of hopelessness, lack of empowerment, low aspirations, reduced self-efficacy and low self-esteem (Glewwe et al., 2018). Benabou and Tirole (2003) argue that empowering and encouraging individuals can increase their self-esteem and it may in turn increase their achievement.

Belief in one's personal efficacy is a statutory mechanism through which, people believe or disbelieve in what is attainable to them by their actions and have incentives or disincentives, respectively, to act accordingly (Bandura, 2015). These efficacy beliefs help individuals decide what goals to set; how much effort to invest; and how much

\footnotetext{
${ }^{4}$ The real education expenditure, as expressed in the total education budget in India doubled between 2004 and 2009 (Muralidharan, Das, Holla, and Mophal 2016) - constituting 3.3 percent of the country's GDP (UNESCO report, 2011) - and has increased thereupon. Most of it focused on improving schooling access and inputs.
} 
perseverance to exhibit in the face of obstacles (Locke and Latham, 1990).

Snyder (2002) defines hope as the perceived capability to derive pathways to desired goals, and motivate oneself via agency thinking to use those pathways. According to Snyder et al. (1991):

"Hope is a positive motivational state that is based on an interactively derived sense of successful (a) agency (goal-directed agency), and (b) pathways (planning to meet goals)"

Implicit to this explanation of hope is the inherent uncertainty about future outcomes that neither the pathway nor the individual agency can determine (Lybbert and Wydick, 2016). According to this definition by Snyder (2002), hope being a motivational state is different from aspirations that are goals themselves shaped by peoples' beliefs (Locke and Latham, 2002). Within the scope of this study, alike La Ferrara (2019), I will focus only on aspirational hope ${ }^{5}$ Aspirational hope, as per Lybbert and Wydick (2016) is more than optimism in so far that there is a strong role for agency in the former, with the latter being devoid of it. This is discussed in more detail in section 5 .

Snyder (2002) critically underlines the significance of pathways by positing goals as unanswered calls without these critical means to reach them. High-hope individuals are flexible thinkers, more capable of finding and/or generating alternate routes, especially in situations with impediments. Moreover, agency thinking, described as the perceived capacity to use ones pathways to attain desired goals, is the motivational component in hope theory and involves mental energy usage to begin and continue using a chosen pathway throughout the process of goal pursuit (Snyder, 2002).

\footnotetext{
${ }^{5}$ Aspirational hope is different from wishful hope. For instance, I hope it does not rain tomorrow Vs. I hope to publish my work in a top Economics Journal. While, the former lacks a goal directed agency and means to reach that outcome, the latter entails a combination of goal-oriented thinking that can serve as a motivation to find alternative means to reach that goal. Snyder (2000) critically draw a distinction between the two, with the former being wishful hope and the latter being an example of aspirational hope, which composes the premise of this study.
} 


\subsection{Theory of Change}

People who doubt their capabilities, often, in the face of difficulties slacken their efforts, give up early or settle for poorer outcomes (Bandura, 2015). Contrastingly, people with strong beliefs, increase their efforts and strive to attain the optimal solutions whilst mastering the challenges (ibid.). Intrinsic to this mechanism, a relationship between hope and effort can be expected, which is yet to be theoretically studied and empirically tested. Hopeful individuals having strong efficacy beliefs about setting and achieving a particular goal, may exert a higher amount of effort vis-a-vis less hopeful ones (Snyder, 2002). Furthering the initial predictions of Snyder's (2002) hope theory, I propose that hope can be a determinant of effort, and eventually achievement.

Banerjee and Duflo (2011), propose hope to be a fundamental capability, akin to health, good nutrition, and education. Duflo (2012) argued that hopelessness (especially, among the poor) is accompanied by low aspirations that foster low investments and consequentially poor outcomes. These investments can be in terms of time, effort or material resources. Hopeful attitudes, on the other hand, can motivate individuals to look for relevant information or find means to a goal: invigorating pathways (Miceli and Castelfranchi, 2010). Hope can thereby be an instigator of higher goals and higher effort, creating a virtuous cycle of successful goal-attainment and attitudes that are more hopeful for the future.

Figure 1 encapsulates the framework of this study, within which, I posit that exposure to motivating videos, can foster hope in students and influence the amount of effort they exert. I propose that hope increases effort. Together, hope and effort, can increase academic performance. Using a role-modelling intervention, I assess the treatment effects on a host of psychological factors (like hope, happiness and self-efficacy), effort and academic achievement of students. 


\subsection{Theory of hope, effort and achievement}

Having discussed the role of hope and effort in successful goal-attainment, the following model attempts describes the relation between hope, effort and achievement. I develop a single agent model. The agent's utility function is defined as follows:

$$
U(e, \delta)=\bar{\theta} p(e, \delta)+[1-p(e, \delta)] \underline{\theta}-c(e)
$$

where $\bar{\theta}$ and $\underline{\theta}$ are the high and low outcome, respectively. $\mathrm{p}$ is the probability and $\mathrm{c}$ is the cost. The agent is endowed with some level ' $\delta$ ' of hope and chooses a level of effort ' $\mathrm{e}$ ' to maximize her/his utility. In this model, the outcome space is binary, i.e. $\{\bar{\theta}, \underline{\theta}\}$. Achievement is stochastic and seen to be dependent on hope and effort. A trade off that the agent faces is that increasing effort raises the chances of achieving the high outcome but simultaneously increases the cost. This decision process takes into account the agent's intrinsic hope.

Before stating the proposition, the following assumptions are introduced:

Assumption 1. The cost function is increasing linearly in effort but it does not cost at all to hope.

$$
c(e)=\alpha e
$$

There is a cost associated with effort, which can be in terms of physical effort, mental stress or time invested. But hope is assumed to be costless.

Assumption 2. The probability associated to the successful realisation of the higher outcome $\bar{\theta}$ is increasing in effort, i.e.

$$
\frac{\partial p}{\partial e}>0
$$

In this case, equation (2) can be seen as the agency of an individual.

Assumption 3. If we have higher hope (or agentic motivation) then the perceived marginal benefit of effort is higher (invigorating pathways). Alternatively, the marginal 
subjective probability of goal attainment with respect to effort is increasing in hope, i.e.

$$
\frac{\partial^{2} p(e, \delta)}{\partial e \partial \delta}>0
$$

Proposition 1. Hope increases effort for a given goal and subjective probabilistic beliefs.

The proposition states that if hope is exogenously increased through 'vicarious effects' (as studied in Bernard et al., 2014 and La Ferrara, 2019), then for an individual with a particular goal, that increase in hope acts as an enabler or facilitator of higher effort. The proof is in the appendix.

\section{Intervention and study design}

\subsection{Sample}

The study was conducted in six schools of India as per the time line in figure 2. The selection strategy ${ }^{6}$ ensured homogeneity across the sample of students. Based on the power calculations recorded in the pre-analysis plan (PAP) 7 , four hundred and fiftytwo class-4 students, aged 9-11 years, were identified from 6 private schools in Jaipur, Rajasthan. Information on school attendance, past academic records and curriculum was collected prior to school identification to maintain comparability across schools. No two schools are farther than $8 \mathrm{kms}$ or closer than $3 \mathrm{kms}$ to avoid compromises on comparability. The sample of students attending the schools are from lower-middle income households.

I conducted this study on class 4 students for three reasons. Firstly, 9-11 year old students are mature enough to comprehend the treatment videos. Secondly, the hope scale has been accepted as a valid instrument to capture hope of children aged

\footnotetext{
${ }^{6}$ Refer table A.1 for the selection strategy that was followed for sample selection.

${ }^{7}$ PAP available at: https://www.socialscienceregistry.org/trials/4454/history/60503. Any departures from the PAP are recorded in the online registry and are explicitly mentioned.
} 
between 7 and 15 years (Snyder et al. 1991, and Snyder et al., 1997) et al. (2013) argue that intervening at an early age has significantly higher benefits.

The average age of students was 9 years with approximately 61 percent of the sample comprising of boys. The majority of the students were Hindu and native to the study location. The students reported studying for 6-7 hours per week with huge variations ranging from 0 to 28 hours, and the median sample studying for 7 hours per week. 45 percent of the students reported taking private tuition. These summary statistics are presented in table A.2.

\subsection{Treatment}

The treatment comprised of a set of three short films $9^{9}$ that were produced in Jaipur, India. The first story is about a young girl, who aspires to become a badminton player, but subject to material constraints, cannot practice. She finds hope, in the form of her best friend who offers her an old racket to practice and hone her skills. She eventually becomes a national level badminton player. The second story is about a young boy, who is aimless but draws inspiration in a guest lecture at his school and ends up becoming an air-force pilot. The last story focuses on a girl from an economically marginalised household. Despite being a good student she has to quit her school due to financial constraints. However, when the opportunity arises in the form of a scholarship test, she is filled with hope, and works very hard to win the scholarship. All the protagonists, end up fulfilling their aspirations, with hope and hard-work.

The movie was produced, keeping in mind, the age, attention-span and comprehension skills of the audience that it caters to. The themes of hope and hard-work were carefully incorporated in the story. Following Lockwood and Kunda, (1997), the movies are carefully produced to ensure relevance and relatability with the pro-

\footnotetext{
${ }^{8}$ Bloem et al. (2018), Guse et al. (2016) and Pulido-Martos (2014) employ CHS in Myanmar, South Africa and Spain to measure hope in children adding to its external validity.

${ }^{9}$ The treatment video in English with subtitles is available at: https://www. youtube.com/watch? time_continue $=365 \& v=-$ VTpyX5LZ5A\&feature $=$ emb_title
} 
tagonists and goal attainability. The intervention carefully projected two female and one male role-model, as female viewers tend to respond better to female role-models, whilst not so much a case for male viewers (Lockwood, 2006).

The placebo group (sometimes referred to as control group 10 ) students watched a kids television show named, Malgudi Days ${ }^{11}$. Set in a fictional Indian town, the video is about a small group of friends that try to bring together a cricket team. An episode from the television series was carefully selected to avoid any potential exposure to motivating or de-motivating subjects. The videos - almost equally entertaining - were tailored in length (30 minutes) to avoid any compliance issues.

The intervention was conducted in the computer laboratory rooms of the schools. Each student was allocated a screen depending on their treatment assignment, along with a pair of earphones. Cardboard pieces were mounted on the screens to avoid any issues of compliance or spillover. Trained fieldworkers ${ }^{12}$ were present at all times during the intervention to ensure compliance and overcome any technical difficulties. An endline data collection round was conducted immediately, preceding two follow-up rounds, 1 and 6-weeks after.

\subsection{Indicators and outcome variables}

The key outcome variables, as explained in table 1, can be broadly categorised into three: hope, effort and achievement. Information on hope is collected using CHS. A novel psychometric data is collected using children's self-portraits. These drawings are analysed to capture psychological traits like happiness and self-efficacy or optimism as in Glewwe et al. (2018). For capturing information on student effort, a substitution class during the school time and a remedial class after school hours were organ-

\footnotetext{
${ }^{10}$ For the tables and figures, I have used ' $\mathrm{T}$ ' and ' $\mathrm{C}$ ' to represent the comparisons between the treatment and placebo groups, respectively.

${ }^{11}$ The placebo video is available in Hindi with subtitles at: https://www.youtube.com/watch?v= noNEijycj1c

${ }^{12}$ Data collectors from Muskaan were recruited and trained over the course of three workshops by the PI in July, 2019.
} 
ised in each wave of data collection. Achievement was measured using standardised ASER-style tests for Maths and English. Information on past-academic performance of these students was collected using school examination records. Further to this end, secondary data on school attendance is also collected.

\subsubsection{Psychological outcomes}

\section{Hope}

CHS produces a measure for children's hope on a scale 0 - 36. The 6-item likert-style scale is administered to the respondents as 'information about yourself' with an extra 10 items to overcome memory effects. These 10 items have no priming effects. The six items include questions on agency and pathways - the two constituents of hope - and for each item the student has to select an option from 'none of the time' to 'all of the time', scored 1 to 6 , respectively. The sum of responses on these 6 items results in a score from 1 to 36 for each student. A surveyor was present in the classroom to make sure that the students do not look at each-others scripts during the process, and fill the CHS independently and thoughtfully.

\section{Happiness and self-efficacy}

Complementing the CHS, a self-portrait task was given to the children. On the footsteps of Glewwe et al. (2018), who performed a quantified analysis of self-portraits of Indonesian children to assess the impact of international child sponsorship program, I collected data on children's portraits of themselves. They were asked to draw a figure of themselves on a mundane subject, 'draw yourself on last Sunday'. A clean sheet of paper and 24 colouring pencils were made available to each student. In addition to the 20 self-portrait characteristics used by Glewwe et al. (2018), I used 10 additional characteristics based on the literature. These characteristics, along with their summary statistics are presented in table A.3. Their empirical correlations are presented in table A.4.

To evaluate the drawings and compute meaningful latent psychological factors, 
I perform an exploratory factor analysis (EFA) following Costello and Osborne (2005). Thereafter, I rotate the factor loadings orthogonally using varimax rotation. This step enables me to have two meaningful factors, with uncorrelated component loadings (Osborne, 2015). Based on the literature (and table A.4), I deduce that the two factors can be labelled as optimism or self-efficacy (Bandura, 1977) and happiness. The rotated factor loadings are presented in table A.5, and the factor compositions for the two factors for self-efficacy and happiness are presented in table A.6 (a) and (b). The generated indices are presented in a single direction of positive impact.

Although hope, self-efficacy and optimism are seemingly overlapping concepts, a key distinction pointed by Magaletta and Oliver (1999) is that hope can include both self-efficacy and optimism within its construct. Optimism or self-efficacy, imply a forecastability of a probable successful goal attainment, which may or may not be the case for hope (Scheier and Carver, 1985). Hope can be premised over events that can be regarded as both controllable or uncontrollable, without a disposition to harbour accompanying positive expectations, as in the case of self-efficacy or optimism (Micheli and Castelfranchi, 2010).

\subsubsection{Effort and Achievement}

\section{Effort}

Effort was measured on two different activities: (i) Optional Remedial Class, and (ii) Substitution Class. For the substitution period, a student was observed thrice in equal intervals and received a score ' 1 ' for each observation that $s$ /he was found to be engaged in a productive activity and ' 0 ' otherwise. This indicator of in-class effort relies on third-party observations made by a surveyor ${ }^{13}$. Upon arrival, the surveyor introduced her/himself as a substitution teacher because the relevant subject-teacher could not be available for this class and announced that the students were free to do anything they wanted. The surveyor was provided with a seating plan that was already double

\footnotetext{
${ }^{13}$ The surveyor was blind with respect to the treatment assignments of these students.
} 
checked. The surveyor marked three intervals of time and observed every student one by one, marking 1 or 0 in the observation sheet if they were observed to be working or otherwise, respectively. The sum of three observational scores, ascribed an aggregate score of 0-3 to each student.

For the optional after-school remedial class, a student received a score ' 1 ' if s/he attended the class and ' 0 ' otherwise. The students had a day in between the date of the announcement by the teacher and the event of the remedial class. This announcement - made after the substitution class - was accompanied by a circular issued by the school authority with the details of the remedial class and its optional nature. In both these instances, the students were unaware that they were being observed to avoid any experimenter demand effects.

\section{Achievement}

To collect information on student's academic performance, I used Pratham's Annual Status of Education Report (ASER) 'floor'- level tests for Mathematics (Maths) and English (Banerjee et al., 2015; and Pratham, 2014). I tweaked these ASER tests to report a score out of 50 for each of the two subjects. Written instructions about the test were also available on the front sheet of the test. It was a 25-minute time-bound task. Alongside, I kept a track of the student's academic performance in school examinations from Class 3 to Class 4 .

In addition to these key outcome variables, baseline survey questionnaires on students were conducted to capture information on confounding factors that do not change due to the treatment. These include age, gender, religion and household size, among other covariates. A detailed explanation about the data collection 4 is presented in the next section.

\footnotetext{
${ }^{14}$ Ethical approval was received from the University of Glasgow's CoSS Ethical Review Committee on July 4, 2019 with reference number: 400180272. The approved start date for the study was July 12, 2019.
} 


\section{Data}

The process of data collection lasted for four months (August-November 2019) $\sqrt{15}$ A team of trained data collectors from Muskaan facilitated the roll out of baseline in August 2019. Data on covariates was collected as a part of an extensive simple-language survey questionnaire for children. A part of this information was later triangulated and validated using similar surveys and interviews with their teachers and parents. Data collection on the outcome variables proceeded in the step-wise fashion as illustrated in table 1.

The same exercise was followed consistently in each school and in each phase of data collection. Data collection was carried out in the school premises. Moreover, I followed Zizzo's (2012) non-deceptive obfuscation when explaining the nature of the experiment to the school authorities and teachers. The RCT was proposed with an objective to study the educational practices in private schools in India. This further avoids the risk of any experimenter demand effects.

\subsection{Baseline Characteristics}

As per table A.2, the average hope of the students in the sample was 27 , with some students scoring as low as 11 and as high as 36. According to Snyder et al. (1998), the global average hope score for students is between 24-28. Hence, it is safe to say that the average student hope levels are neither too low or high. Each student was observed to on an average engage once in a productive activity out of the three observations made during the substitution class at baseline. The attendance for the optional remedial class, was around 35 percent at baseline, with high standard deviations for both measures of effort. The average scores on Maths and English were 32 and 31, respectively, out of 50. An overall average score of 63 out of 100 with a standard deviation of 34 , correlated positively with the exam performance of these students in class 3.

\footnotetext{
${ }^{15} \mathrm{~A}$ video summary of the data collection process in English with subtitles can be found at: https: $/ /$ www youtube. com/watch?v=1zOBCaZ-VEQ\&t=2s
} 
The measures of hope and effort, very much like my theoretical model, intuitively predict student performance. Table A.7 presents the baseline relationships between the different covariates and variables of interest. Column (1) and (2) show that past performance is a significant predictor of future performance. Achievement proxied by the ASER-style test scores, is positively related with higher effort and optimism. Hope and effort (measured by substitution and remedial class) are strongly positively related with achievement. Other confounding variables like gender or household size do not relate to the variables of interest.

To explore the treatment effects, I randomised the students at individual level to overcome any systematic differences that may prevail between the otherwise similar students across different schools. The randomisation process and balance are discussing in the next section.

\subsection{Randomisation}

Randomisation - performed during baseline using excel - allocated the pool of students into two groups, details to which were withheld from everyone apart from the research staff. Subject to the group that they were assigned to (treatment or placebo), the students were taken to their school's computer lab by a school teacher and a surveyor. Each student watched the video assigned to her/him individually.

\section{Balance}

Balancing checks based on gender, age, religion and past performance of students were performed during the baseline. As evident in table 2, the two groups are not systematically different from each other based on any of the baseline characteristics in covariates. The same applies for baseline scores on hope, effort or achievement measured using the survey instruments or children's drawings.

By construct, the students did not have the occasion to interact between intervention and endline. However, the students could interact between endline and the two follow-up surveys. Even though the treatment or placebo videos were deleted 
from the school computers on the day of the intervention, all possibilities of spillovers are not subdued over the final follow-up rounds, 1 week and 6 weeks after the intervention. I am unable to unearth the potential of, albeit small, spillovers that may exist due to conversations among friends and peers (as found in Duflo and Saez, 2003). Nonetheless, these spillover - if they exist - strengthen my argument on cost effectiveness of the treatment under a moderate assumption of the presence of social learning among peers (Conley and Udry, 2010, and Macours and Vakis, 2014).

\section{Attrition and compliance}

Attrition was estimated based on the existing literature. While differential attrition is a cause of concern, most of the information was collected as a continuous classroom exercise based on carefully devised indicators to minimize the potential threats from it.

As shown in table A.8, attrition was balanced across the two groups. I report the attrition balance test for CHS, portraits and substitution class. The balance holds in the same manner for all the other outcome variables due to the nature and design of the data collection process. As the different instruments are administered on the same day during school hours, one after the other, it leaves no room for attrition to be different for the measures of effort and achievement in any data collection round after baseline.

\section{Empirical strategy and results}

\subsection{Empirical specification}

I use a difference-in-differences (DiD) approach to assess the impact of the intervention, using:

$$
Y_{i t}=\alpha_{0}+\alpha_{1} T_{t}+\alpha_{2} D_{i}+\alpha_{3}\left(D_{i} T_{t}\right)+\alpha_{4} X_{i t}^{\prime}+\epsilon_{i t}
$$

where the main outcome variable $Y_{i t}$ corresponds to the variable of interest for individual $i$ at time $t . D_{i}$ is the dummy for individual treatment, being 1 if the the individual 
is in the treatment group and 0 for placebo. $T_{t}$ is a dummy for time or sessions. $X_{i t}^{\prime}$ is a vector of covariates. The coefficient $\alpha_{3}$ of the interaction term $D_{i} T_{t}$ captures the treatment effect. I employ the same specification for portrait analysis.

Since the outcome variables are not very strongly autocorrelated, ancova offers a higher power (McKenzie, 2012). To assess the intent-to-treat (iTT) treatment effect, I use ancova:

$$
Y_{i t}=\beta_{0}+\beta_{1} Y_{i 0}+\beta_{2} X_{i t}^{\prime}+\beta_{3} D_{i}+e_{i t}
$$

where $Y_{i 0}$ is the baseline measure of the outcome variable. $Y_{i t}$ corresponds to the dependent variable, which is the outcome variable in the follow-up rounds, including endline. $\beta_{3}$ captures the treatment effect. Further to this end, ancova enables the estimation to examine the overall treatment effect across the subsequent follow-up rounds, providing additional power (by pooling several rounds of follow-up data):

$$
Y_{i t}=\sum_{t=1}^{q} \delta_{t}+\beta_{1} Y_{i 0}+\beta_{2} X_{i t}^{\prime}+\beta_{3} D_{i}+e_{i t}
$$

where $q$ is the number of follow-up surveys and $\delta_{t}$ is the survey round dummy, with $\beta_{3}$ capturing the overall average treatment effects.

In equations (4), (5) and (6), the individual characteristics that I include as controls $\left(X_{i t}^{\prime}\right)$ consist of age (measured in years), gender ( 1 for boys and 0 for girls), household size (number of individuals living in the same household), students' past academic performance (percentage scored in class 3 examinations) and religion (1 for Hindu and 0 otherwise). I report robust standard errors that are clustered at an individual level to account for heteroskedasticity.

\subsection{Main results}

Table 3, presents the DiD estimates for the main outcome variables. Column (8) and (9), show the treatment effect without and with the controls, respectively. The results 
are standardised and presented in $\mathrm{sd}^{16}$. In column (9), I find that hope increased by $0.17 \mathrm{sd}$, along with a $0.26 \mathrm{sd}$ increment in effort during the substitution class, both of which, are significant at 5 percent level of significance. I find no effect on remedial class and achievement immediately after the treatment. However, it is expected as improvements in learning outcomes pursue a gradual process.

Following equation 4 , table 4 , summarises the treatment effects over the different periods in time. Column (1) and (2) show the treatment effects without and with controls, respectively, immediately after the intervention. Column (3) and (4) show the effects 1 week after the intervention; and column (5) and (6), provide the estimates six weeks after the intervention, in a similar way.

As predicted, the lagged benefits from the small increase in hope and effort in substitution class, are complimented by an improvement of $0.12 \mathrm{sd}$ and $0.16 \mathrm{sd}$ in English scores, 1-week and 6-weeks after the treatment. These effects are significant at 10 (1-week after) and 5 (6-week after) percent level of significance, after controlling for individual characteristics. I find no change in the math scores. Although the increase in hope and effort in substitution class is significant only in the first two columns, the effect on self-efficacy is significant and stronger after 6 weeks.

Using equation (5) and (6), and marking an extension to my PAP, I assess the treatment effects using Ancova, much in lines with McKenzie (2012), Riley (2017), and Glewwe et al. (2018). For overall treatment effects, across the subsequent rounds of follow-ups, I adopt the approach by Bloom et al. (2013), de Mal et al. (2014) and Beath et al. (2013). Table 5, presents the effects from ancova, with column 1, 2 and 3 representing the effects in each follow-up and column 4 and 5 presenting the overall treatment effect without and with controls, respectively using the pooled dataset.

The short-run treatment effects are similar in magnitude to table 4, but strongly significant, highlighting the additional power from ancova (Wydick et al., 2018). Column 5 , shows that the treatment, on average, increased effort in the remedial class by

\footnotetext{
${ }^{16}$ Cohen's D.
} 
$0.17 \mathrm{sd}$ and English scores by $0.11 \mathrm{sd}$ at 1 percent significance level. This offers some descriptive evidence that a temporarily detectable increase in hope, in the short run, can potentially result in significant improvements in student effort and achievement. Moreover, the overall treatment effect on hope is also positive, although insignificant.

\subsubsection{Hope}

Hope, measured by Synder's CHS ${ }^{17}$, recorded an increase of 0.17 sd immediately after the intervention, as can be seen in figure 3 (a). To investigate this further, I plotted a kernel density estimate that in figure 3 (b) shows the distribution across the sample. The small rightward shift in the treatment group students' hope in the overall s-shaped curve (Banerjee and Duflo, 2011), is suggestive of the effect. The largest shift happens in the bottom most part of the curve, indicating some heterogeneity in the treatment effects based on the baseline hope levels that is discussed later.

I argue that a small shift in hopefulness can initiate a virtuous cycle of higher hope and effort in the short run and higher achievement in the longer-run. Moreover, this small increase in hope can act as a fundamental capability that can fuel and sustain other positive psychological traits among the students, descriptive evidence to which is offered as a part of this paper. Panel (a), (b), (c) and (f) of figure A.1 illustrate this using point estimates of treatment and control group averages for hope, self-efficacy, effort in remedial class and achievement in English scores, respectively.

Panel (a) of figure A.1 plots the hope score averages (in s.d.) for the treatment and placebo groups across the four rounds of data collection. There is a drastic increase in hope of the treatment group (in blue) after the intervention with the overall effect sustained over time. However, I cannot detect this effect as hope of the control group students (in red) also starts to rise after the endline, potentially due to peer effects and spillovers from the more hopeful and optimistic treated cohort. As for self-efficacy or optimism, in panel (b), there is somewhat smaller increase in the placebo group,

\footnotetext{
${ }^{17} \mathrm{CHS}$ is included in the appendix figure A.3.
} 
allowing detectable effects in the follow-ups. The objective measures of effort and achievement in panel (c), (d), (e) and (f) do not entail potential spillover effects.

\subsubsection{Self-portrait analysis}

Koppitz (1968) suggests that children's drawings reveal subtle and insightful information about their mental health, which is difficult to obtain by asking straight questions. For instance, the choice of dark over light colours is correlated to depression and anxiety, tiny figures with low self-esteem and monstrous figures with aggression (Koppitz, 1968). Farokhi and Hashemi (2011) consider drawings as a communicative tool and propose that by observing and analysing the drawings of children, insights on the social, emotional, physical, and intellectual development of children can be gathered.

A figure with a missing mouth, nose or eyes is correlated with traits of insecurity or depression (Koppitz, 1968; Klepsch and Logie, 1982; Di Leo, 1983). Opposing a smiling face that corresponds to happiness, a sad or crying face is associated with anxiety or unhappiness (Furth, 2000). Positive accessorisation or body language are seemingly more contextual and indicative of higher self-efficacy or optimism (Klepsch and Logie, 1982; Farokshi and Hashemi, 2011). Each characteristic in table A.3, if manifested in the drawing, received a score 1 (and 0 otherwise). Each of these codes were cross-verified and processed only after a consensus was arrived upon.

For further robustness, alike Glewwe et al. (2018), I prepare two standardised indices, for self-efficacy or optimism. For creating these indices, I normalise the factor by demeaning it and dividing it by the baseline standard deviation, after ordering them in a single direction of impact on a psychological trait. I follow the approach by Kling et al. (2007), and produce an average of these normalised variables. To generate the second index, I follow Anderson (2008), and multiply an inverted variance-covariance matrix to the normalised index. This process assigns a higher weight to the drawing characteristics possessing more independent information or having lower covariance with respect to other characteristics. Each variable $i$ in a group $j$ receives a weight of 
$\bar{s}_{i j}=\left(1^{\prime} \sum^{-1} 1\right)^{-1}\left(1^{\prime} \sum^{-1} y_{i j}\right)$. For the remaining part of the paper, I refer to them as Kling's index and Anderson's GLS 18 index 19 .

Figure A.2, illustrate the baseline variations across these factors in the drawings. Panel A reports the baseline self-efficacy/optimism measures ranked at 5th and 95th percentile ( $\mathrm{a}$ and $\mathrm{b})$, respectively. The drawing in Panel A (b) shows the use of cheerful colours, with a smiling face and positive accessorisation and positive body language. Contrarily, the first figure, depicts a rather plane-faced figure, without a smile and missing limbs. Panel B reports the measures for happiness ranked at 5th and 95th percentile (c and d), respectively. In figure (c), adding to the disproportionate figures and lack of colours, there are significant erasure marks. However, the top happiness percentile student in figure $(\mathrm{d})$ is smiling, having a positive body language on a ride with her/his father. These characteristics, as depicted in table A.6 are correlated with relevant positive and negative psychological indicators.

Table 6 presents the treatment effects on these factors prepared using children's drawings. Employing equation 4, I find that self-efficacy scores of children increase by $0.28 \mathrm{sd}$ immediately after the intervention. The effect weakens slightly one week after and reduces in significance to $0.23 \mathrm{sd}$; but is sustained six weeks after at $0.34 \mathrm{sd}$. This effect is strongly significant and smaller in magnitude, for Kling's and Anderson's index. Since, each method has its advantages and shortcomings 20 , I present results for each of the three indices. Happiness started rising 1 week after the intervention and the effect remained constant at $0.20 \mathrm{sd}$ after six weeks. This effect is significant at 10 percent.

\footnotetext{
${ }^{18}$ GLS - generalised least square

${ }^{19}$ Kling's index gives equal weight to each characteristics, whereas Anderson's index has lower weight assignments to characteristics that are strongly correlated with other characteristics, in that index

${ }^{20}$ While EFA results in a composite index of correlated characteristics that are identified as indicating a latent psychological characteristic, Kling and Anderson's index are more theory directed and eliminate (or add higher weight to) unrelated (strongly related) codes within these variables, in the process adding to the precision of these indices.
} 


\subsubsection{Effort and Achievement}

I capture the effect of the intervention on both in-class and out-of-the-class effort, using the substitution class and remedial class indicators. Referring table 4, I find an increase of $0.26 \mathrm{sd}$ at 5 percent significance level in the substitution class. This implies that right after the intervention, the students were motivated to engage in a productive activity for when the occasion in the form of a free-period arose. This can range from completing their homework, reading a textbook or making notes. However, this effect was short-lived and evaporated in one week.

Table 4 and figure A.1 (c) show that even though the attendance in the remedial class improved largely over and above the control group, there are no detectable effects. Nevertheless, using equation 6, I find that the overall treatment effect - as shown in table 5 - is highly significant for remedial class attendance, which increased by 0.17 sd towards the culmination of the final follow-up survey. There is a twofold explanation for this based on figure A.1 (c), and table 4 and 5 .

Firstly, comparing the sample sizes in column 1, 2, 3 and 5 in table 5, it is reasonable to argue that I have much higher power to detect smaller effects when looking at overall treatment effects against effects in a single round of data collection. In this manner, this study, like Bloom et al. (2013) and McKenzie (2012), underlines the powerbenefits of ancova regressions. Secondly, attending the optional after-school remedial class required effort from not only the children (unlike the substitution class) but also their parents. For each student that stayed back to attend the class, alternative pick-up arrangements, were to be borne by the parents. For instance, a child who would use a school bus or van, could not take it if $\mathrm{s} /$ he were to attend the remedial class. Based on some follow-up interviews with the teachers, it is argued that the lack of effect could be a result of lack of support from parents due to binding resource constraints that are not addressed from the purely psychological nature of the treatment.

It is expected that it took some time for the otherwise willing students to convince their parents to seek out alternative arrangements to facilitate their attendance. 
This systematically lagged and gradual effect is captured in column 5 of table 5 . I argue that eventually, children of the treatment group that were keen to work harder were able to convince their parents to allow them to stay back to attend the remedial class. Simultaneously, the parents also had a larger window of adjustment period to identify other means to pick-up their kids from school at a later time, over these six weeks.

Table 4 shows that English scores start improving moderately one week after the intervention (0.12 sd at 10 percent significance level). I find that after six weeks English scores increase by $0.16 \mathrm{sd}$. The overall treatment effect as per table 5 is $0.11 \mathrm{sd}$ for English. I do not find any effect on Math scores. The point estimates for these are presented in figure A.1 (e) and (f).

\subsection{Heterogeneous effects}

I analyse the data to see any differential effects that may persist due to the confounding variables like gender and age on these variables of interest. As the intervention had both female and male role-models, it may be possible to have heterogeneous effects based on the gender of the student. Similarly, age, as postulated by Heckman et al. (2013), can be a strong determinant for this heterogeneity. Heckman et al. $(2013,2006)$ and Heckman and Kautz (2012) find that soft skills and motivation, among other psychological characteristics, when intervened at an early age, can have fruitful outcomes in adulthood. In addition to this, the baseline hope level of the student can also be a cause for heterogeneity.

In order to examine the heterogeneous effects ${ }^{21}$, I modify the DiD equation (4) to:

$$
Y_{i t}=\alpha_{0}+\alpha_{1} T_{t}+\alpha_{2} D_{i}+\alpha_{3}\left(D_{i} T_{t}\right)+\alpha_{4} X_{i t}^{\prime}+\alpha_{5}\left(X_{i t}^{\prime} D_{i}\right)+u_{i t}
$$

where $\alpha_{5}$, the coefficient of the interaction term $\left(X_{i t}^{\prime} D_{i}\right.$ captures the heterogeneity in treatment. To capture heterogeneity, firstly I created an indicator for gender (male - 1

\footnotetext{
${ }^{21}$ In the PAP, I mention exploring heterogeneity along age, gender and baseline hope quantiles. An addition is to further explorations of heterogeneity along past academic performance.
} 
for boys and 0 for girls). Secondly, I created a dummy for students above the median age (9 years). Thirdly, based on the performance in class 3 examinations, I created a binary variable for above median performing students. Lastly, using the baseline CHS scores, I prepared quantiles on hope.

Heterogeneous effects based on gender, age and former performance on psychological factors like hope, self-efficacy and happiness are presented in table 7 panel (a). These effects on effort and achievement are presented in panel (b). As can be seen in panel (a), younger students increase their self-efficacy more than the older cohort. This is indicative, towards the higher effect an early age intervention can have (Heckman et al., 2013). This effect is strongly significant. In panel (b), students that performed better in class 3 examination, are more likely to exert higher effort in attending an optional remedial class. However, the treatment effect on effort is not significant.

I do not find any heterogeneous effects for gender. This can be because the treatment consisted of two female and one male role-model. According to Lockwood and Kunda (1997), female viewers respond to a female role-model, whereas, male viewers respond well to both male and female role-models. Bettinger and Long (2005) find that female course instructors in Ohio, unlike their male counterparts, can influence course selection and major choices, acting as role models. Riley (2017), finds a similar treatment effect on girls, who benefit more than boys, from watching a film comprising of a female role-model. The content of the intervention video, therefore, balances the treatment effects across gender. However, upon further exploration of an interaction of gender and age in table 8 , I find that younger girls responded by increasing their selfefficacy by 0.42 sd over and above the younger male cohort. This is effect is significant at 10 percent.

Looking at the subsection of the sample, segregated by baseline hope quantiles, as depicted in table 9, I find that the lowest hope quantile showed the highest increase of 0.23 sd significant at 10 percent. The students in the second quantile showed higher improvements in remedial class attendance $(0.36 \mathrm{sd})$, Math $(0.31 \mathrm{sd})$ and English $(0.27$ 
sd). However, the treatment effect is insignificant on remedial class or achievement indicators. For substitution class, students belonging to the third quantile reported a higher increase by $0.28 \mathrm{sd}$ at 10 percent. However, the highest hope quantile students, did not increase their effort in substitution class or their performance in ASER tests.

\subsection{Robustness}

I winsorize my sample outcome variables at 1 (and 99) and 5 (and 95) percent and perform a DiD estimation. Table A.9 shows that the results are unaffected for effort and achievement. Similarly, table A.10 shows that the effects are unchanged for psychological traits in panel (a). In panel (b) of table A.10, the effects are slightly smaller and less-significant, which is expected at 5 percent level of winsorizing.

As a second robustness check on the outcomes for effort, I look at the effect of the intervention on students' school attendance. Since, this indicator was not originally recorded in the PAP, I use it for robustness checks.

School attendance, as generally observed, is a strong objective indicator of effort. Each student that attends a day when the school is operative, receives a score 'one' for that day and 'zero' otherwise. I tracked the attendance data of students between July 2019 and January 2020. Final class 4 examinations were conducted within the schools in February-March 2020, which enabled me to compare the effect of the intervention over a year long period $^{22}$. I use equation 5 for assessing treatment effects on the school attendance of students.

As the intervention was conducted in the last week of August, 2019, I treat the attendance fractions 23 for that month as the baseline attendance score. As in table A.11, I find no improvements in the attendance in the month of September, October, November or December. However, I find a $0.02 \mathrm{sd}$ increase in the attendance of the

\footnotetext{
${ }^{22} \mathrm{An}$ academic year in India is from April to March with summer holidays in May and June. Therefore, I can track students based on their attendance records for the seven months between July 2019 and February 2020 excluding vacations and examination periods.

${ }^{23} \mathrm{An}$ attendance fraction score for each student is created by dividing the number of days that the student attended the school with the number of days that the school was functional in that month.
} 
treated students in January, which is significant at 5 percent. Upon using DiD in table A.12, as in equation (4), I find that 5 months later, the treated students' attendance increased by $0.02 \mathrm{sd}$. As shown in column (6) of table A.11 the overall average treatment effect is an increase of $0.02 \mathrm{sd}$ in student attendance, which is strongly significant. This, as illustrated in figure A.1 panel (d), hints the lasting effects of the treatment.

Thirdly, in case of the portraits, as the factors are composed of several codes, I adopt Anderson's (2008) family-wise error rate (FWER) adjusted p-values, as a final robustness check on the factors created using EFA 24. Table A.13 illustrates that the unadjusted or naive p-values and the FWER adjusted p-values are not very different from each other. The results, are still significant at 10 percent and I can reject the null hypothesis that the treatment does not have any effect on self-efficacy or optimism.

As a final round of robustness check, I conducted several interviews with the teachers in the six schools. The objective of these respondent verification interviews was to cross-validate my findings. The teachers unanimously pointed out that for a short period of time after the study, there were marked improvements in overall student behaviour, punctuality and homework completion rates. As teachers did not have access to neither effort, CHS or ASER scores of students, nor the knowledge of the intent of the study, these findings are credible.

\section{Discussion}

Hopefulness precedes self-esteem and efficacy - acting as a guide towards self-worth by heightening the perception of a child with which they can attain their desired goal (Snyder et al 1997). Perceived hopeful thoughts can drive appraisals in self-worth,

\footnotetext{
${ }^{24}$ I use the codes provided by Dr. M. L. Anderson, following Anderson (2008) to sort the observed p-values and generate simulated p-values from running 10,000 iterations. Exploiting a step-down procedure, I replace the simulated p-values with the minimum of the set of simulated p-values associated with the outcome having observed p-values greater than or equal to the ones that are replaced, keeping a count of such replacements. Following a final ordering adjustment - enforcing monotonicity by going from smallest to largest p-value - I arrived at the FWER-adjusted p-values corresponding to the naive observed p-values. These are reported in Table A.13.
} 
through higher agentic thinking. Although the increase in hope scores is not detected after one-week, the same treatment has a rather long lasting effect on self-efficacy or optimism. This is depicted in panel (a) and (b) of figure A.1. Kliewer and Lewis (1995) argue that higher hope children, remain mentally energised to find encouragement through role-models of all sorts, which eventually manifest in higher learned optimism or efficacy, over time. Corollary to this, I find that happiness starts to increase a week from the intervention and the effects remain significant six weeks later. It is the increased self-efficacy and optimism that overtime seep into correlated feelings of happiness among the students.

There is a short-lived increase in effort in the substitution class immediately after the intervention but I do not detect any effect in the attendance of the remedial class. This is due to the fact that the latter requires a lot more effort on the part of students to not merely attend the class, but also to convince their parents to find means to let them. Panel (c) of figure A.1 suggests that, after a period of adjustment, the treatment group students attend more remedial classes in the follow-ups, with the overall treatment effect of $0.175 \mathrm{sd}$, significant at 1 percent.

Much alike Duflo et al. (2011) and Glewwe et al. (2010), I find a 0.16 sd increase in standardised English test scores at the end of 6 weeks. However, I find no effect on Math test scores. This is due to the floor-level nature of the test and the distinct curriculum followed in the two disciplines. The treatment stimulated improvements in language learning, which is less sequential and synchronous than Mathematics, allowing for quicker and sharper gains in a relatively shorter span of time.

There is a threefold explanation for these findings. Firstly, a short push in student hope precedes improvements in student effort, happiness and achievement. This is not to say that hope increases performance, but to instead offer, suggestive and confirmatory evidence on hope's predictive powers. Secondly, the improvements in student effort and achievement are not driven by a pygmalian effect, as the teachers are to-date unaware of the intentions of the study and the measurement instruments. Fur- 
thermore, the teachers do not know about the treatment assignment of the students, that prevents any systematically differential perception of any individual or group of students. Finally, I find that younger students respond strongly by raising their optimism more than the above median age cohort. This is indicative of the significance of intervening at an age as early as the initial years of the primary school.

While I find that a short role-modelling intervention can increase student hope, effort and achievement, it will be very interesting to see how much of these improvements in effort and achievement are credited to hope. This decomposition of findings is yet to be undertaken. It would be equally useful to analyse the role of other psychological factors like self-efficacy and happiness.

\subsection{Cost effectiveness and policy implications}

Several randomised evaluations that have been undertaken in the past two decades to either improve school enrolment or the learning outcomes of the already enrolled students have contributed to a widespread consensus on the significance of both supply side interventions that address resource constraints and the treatment interventions that address internal constraints. Kremer et al (2013), in a seminal short paper, summarised these studies, of which, I discuss a few, subject to their relevance in my treatment design or comparability in the treatment effect sizes.

Baird et al (2011), found conditional cash transfers to have an effect of 0.14 sd on standardised English test scores in Malawi. Unlike Baird et al (2010), Bettinger (2012) in his study on the effect of financial incentives on elementary school test scores in Ohio - United States, found an effect of $0.15 \mathrm{sd}$ on maths, with no improvements in any other discipline. A remedial education program increased overall average test scores of students in India by $0.28 \mathrm{sd}$, largely with the bottom quantile students improving the most (Banerjee et al 2007). A computer assisted learning (CAL) program increased math test scores by $0.47 \mathrm{sd}$, with the effects receding to $0.10 \mathrm{sd}$, yet persisting after a year (ibid.). These supply side interventions are comparable in effect sizes to many 
recent role-modelling interventions that are at least as cost-efficient if not cheaper to contend a strong policy potential.

Cost-effectiveness, is one of the strongest points of role-modelling interventions. It costed 1200 GBP (1630 USD) to produce the treatment videos for 452 students, with 450 USD of additional administrative costs (procurement of earphones and facilitations in the computer lab). Hence, the cost of the treatment video per student comes down to 4.6 USD. It is not an exaggeration to assume these students to be representative of all the class 4 students going to private schools in urban areas of Rajasthan. Nevertheless, for simplicity and external validity concerns, I will restrict the attention only to these 452 students for any further arguments within this section.

It costed 4.6 USD to increase the English scores by 0.16 sd. Following Kremer et al. (2013), to compare my results with other interventions in education, I extrapolate this effect for every 100 USD spent. The findings in this study are comparable to several other studies and to some extent better in terms of the immediacy of effects.

I find that for every 100 USD spent, it is possible to increase the English score by $3.5 \mathrm{sd}^{25}$. This effect is comparable and modestly larger than Duflo et al. (2011) through teacher tracking and incentives. Duflo et al. (2011) find a 0.16 sd improvement in English scores and a total score improvement of $0.17 \mathrm{sd}$, eighteen months after the program evaluation in Kenya. Glewwe et al. (2010) in another teacher incentive program in Kenya, found a similar effect of $0.15 \mathrm{sd}$, two years through the program implementation. Banerjee et al. (2007), as discussed formerly, find an average test score improvement of $0.28 \mathrm{sd}$ (with $0.47 \mathrm{sd}$ in maths scores) from a remedial education program (and CAL intervention) in India. These effects were recorded 2 years after the treatment, and sustained for over a year after the follow-up. The individual treatment effect on English scores that I find 6-weeks after the treatment are comparable to what Baird et al. (2010) find after a two-year period. In terms of immediacy of effects, my findings are the closest to Riley (2017), with a 2.2 to $2.6 \mathrm{sd}$ improvement in maths, one

\footnotetext{
${ }^{25}$ If score for 1 student can be reaised by 4.6 USD, then with 100 USD, scores for almost 22 students can be raised.
} 
to four weeks after the treatment in Uganda.

Glewwe et al. (2018), in their assessment of Compassion International Child Sponsorship Program find that hope, self-efficacy or optimism and happiness of children increased by $0.32 \mathrm{sd}, 0.68 \mathrm{sd}$ and $0.40 \mathrm{sd}$, respectively. These effects were reported using Children's drawings in Indonesia. My findings mirror these, with the immediacy of effect being as early as right after for self-efficacy and 1-week for happiness. For every 100 USD spent, my findings pertain to increasing hope, optimism/self-efficacy and happiness by $3.6 \mathrm{sd}, 6 \mathrm{sd}$ and $4 \mathrm{sd}$, respectively.

Paying attention to the thought processes of humans (processes of mind), the significance of history in shaping thinking (influences from the society) and other human factors, can substantially contribute towards the effective redesigning and implementation of development policies and interventions (World Development Report (WDR), 2015). Most people care about the behaviours and attitudes of others and imitate (or reciprocate to) them almost automatically (WDR, 2015). I exploit this underlying effect that role-models - in this study, the comparably relevant protagonists - can have on the viewers, if the goals set and achieved by the role-models are seemingly attainable. Although the sustainability of these effects still remains an avenue that requires further exploration, it promises to be a subject of fruitful research and policy potential.

\section{Conclusion}

Perceiving hope as a critical instrument for development, this paper attempts to understand its fundamental implications on primary school children in India. Hopeful children can imagine and embrace goals, envisioning different means (pathways thinking) and initiating or sustaining efforts to achieve them (agentic thinking) (Snyder et al., 1997).

My empirical findings on children's psychological outcomes (hope, happiness 
and self-efficacy), their effort (in- and out-of-school) and academic achievement demonstrate the potential of role-models in treatment interventions. Psychological well-being, closely associated with developmental outcomes, can be improved by exposing individuals to seemingly relatable role-models having attainable goals. I find that a 30minute long carefully designed video, increased students hope by $0.17 \mathrm{sd}$ in the short run. This increase in hope is complimented by increments in self-efficacy (0.15 sd), effort $(0.17 \mathrm{sd})$ and academic achievement (0.11 sd in English scores) in the medium-run.

Internal constraints, being closely related to aspirations, are precursors to a behavioural poverty trap (Ray, 1998 and 2006; Appadurai, 2004; and Walton and Rao, 2004). Dalton et al. (2016) argue that aspiration failure is a consequence, rather than a cause of poverty traps. Banerjee and Duflo (2011), likewise, argue that a similar hopelessness based poverty trap stifles the capacity to aspire, seeing hope as a fundamental capability in Sen's (1973 and 1999) terms. Sachs (2005), Balboni et al. (2019), and La Ferrara (2019) argue towards the implicit importance of a "big push" to escape the aspiration trap very much like in someone's resource endowment.

I propose that such a push can be obtained through an increase in the hopes of individuals, which in itself can influence a host of different characteristics like optimism or self-efficacy including aspirations, functioning as a fundamental capability. There is a twofold advantage: (a) being aloof of expectations, this increase in hope will not have the threat of creating unrealistic expectations or disappointments (Ray 2006) as it might happen by widening the aspiration window too much; and (b) as demonstrated, it can be done in a cheap scalable way.

It will be interesting and extremely useful to evaluate the sustainability of these effects in the long-run. Moreover, it may be the case that the effect amplifies over a longer period of time or becomes visible on non pre-specified outcome variables like school attendance. Furthermore, the optimal duration and content of such treatment interventions remains to be an avenue of further research.

Exposure to optimistic and hard-working role models, led the viewers to believe 
in themselves, become hopeful and over time increase their academic scores. Growing up, children get exposed to numerous films, tv shows and audio-visual content, inside and outside their school premises. This research offers a simple yet profound way to channel hopefulness in the lives of these children and in the process, making them more hard-working. Together, hope and effort, hold mighty potential to elevate the career trajectories of these students and enhance their labour market outcomes.

Hope is real. 


\section{References}

[1] Anderson, M. L. (2008). Multiple Inference and Gender Differences in the Effects of Early Intervention: A Reevaluation of the Abecedarian, Perry Preschool, and Early Training Projects. Journal of the American Statistical Association.

[2] Appadurai, A., (2004). The capacity to aspire. Culture and public action, pp.59-84.

[3] Baird, S., McIntosh, C., and Özler, B. (2011). Cash or condition? Evidence from a cash transfer experiment. The Quarterly Journal of Economics, 126(4), 1709-1753.

[4] Baird, S., Mcintosh, C., and Özler, B. (2016). When the Money Runs Out Do Cash Transfers Have Sustained Effects on Human Capital Accumulation? World Bank Policy Research Working Paper.

[5] Balboni, C., O. Bandiera, R. Burgess, M. Ghatak, and A. Heil (2019). "Why Do People Stay Poor? Technical Report, London School of Economics and Political Science, London, United Kingdom.

[6] Bandura, A. (1977a). Self-efficacy : the exercise of control. Psychological Review, 84(2):191215.

[7] Bandura, A., (2015). Cultivate self-efficacy for personal and organizational effectiveness. Handbook of principles of organization behaviour: Indispensable Knowledge for Evidence-Based Management, 2, pp.0011-21.

[8] Banerjee, A. V., Cole, S., Duflo, E., and Linden, L. (2007). Remedying education: Evidence from two randomized experiments in India. Quarterly Journal of Economics.

[9] Banerjee, A. V., Banerjee, A., and Duflo, E. (2011). Poor economics: A radical rethinking of the way to fight global poverty. Public Affairs.

[10] Banerjee, A., Banerji, R., Berry, J., Duflo, E., Kannan, H., Mukherji, S., and Walton, M. (2015). Teaching at the right level: Evidence from randomized evaluations in India. NBER Working Paper, 22746. 
[11] Beaman, L., Duflo, E., Pande, R., and Topalova, P. (2012). Female leadership raises aspirations and educational attainment for girls. Science, 335(6068):582586.

[12] Beath, A., Christia, F., and Enikolopov, R. (2013). Randomized impact evaluation of Afghanistan's national solidarity programme.

[13] Benabou, R., and Tirole, J. (2003). Intrinsic and extrinsic motivation. The Review of Economic Studies, 70(3), 489-520.

[14] Bernard, T., Dercon, S., Orkin, K., and Taffesse, A. (2014). The future in mind: Aspirations and forward-looking behaviour in rural Ethiopia. London: Centre for Economic Policy Research.

[15] Bertrand, M., Karlan, D., Mullainathan, S., Shafir, E. and Zinman, J. (2005). What's psychology worth? A field experiment in the consumer credit market. Yale University Economic Growth Center Discussion Paper no. 918

[16] Bettinger, E. P. (2012). Paying to learn: The effect of financial incentives on elementary school test scores. Review of Economics and Statistics, 94(3), 686-698. Chicago.

[17] Bettinger, E. P., and Long, B. T. (2005). Do faculty serve as role models? The impact of instructor gender on female students. American Economic Review, 95(2), 152-157.

[18] Bloem, J. R., Boughton, D., Htoo, K., Hein, A., and Payongayong, E. (2018). Measuring hope: A quantitative approach with validation in rural Myanmar. The Journal of Development Studies, 54(11), 2078-2094.

[19] Bloom, N., Eifert, B., Mahajan, A., McKenzie, D., and Roberts, J. (2013). Does management matter? Evidence from India. The Quarterly Journal of Economics, $128(1), 1-51$.

[20] Chong, A., and Ferrara, E. L. (2009). Television and divorce: Evidence from Brazilian novelas. Journal of the European Economic Association, 7(2-3), 458-468.

[21] Conley, T. G., and Udry, C. R. (2010). Learning about a new technology: Pineapple in Ghana. American Economic Review, 100(1), 35-69. 
[22] Costello, A. B., and Osborne, J. (2005). Best practices in exploratory factor analysis: Four recommendations for getting the most from your analysis. Practical assessment, research, and evaluation, 10(1), 7 .

[23] Curry, L. A., Snyder, C. R., Cook, D. L., Ruby, B. C., and Rehm, M. (1997). Role of hope in academic and sport achievement. Journal of Personality and Social Psychology. $73,12571267$.

[24] Darabont, F., and King, S. (1994). The Shawshank redemption: The shooting script [Motion picture]. New York: Newmarket Press.

[25] Dalton, P. S. (2009). Behavioural Decisions: Theory, Implications and Applications (Doctoral dissertation, University of Warwick).

[26] Dalton, P. S., Ghosal, S., and Mani, A. (2016). Poverty and aspirations failure. The Economic Journal, 126(590), 165-188.

[27] Dalton, P., Rschenphler, J., Uras, B. and Zia, B. (2020). Curating Local Knowledge: Experimental Evidence from Small Retailers in Indonesia. The World Bank Policy Research Working Paper 8933.

[28] De Mel, S., McKenzie, D., and Woodruff, C. (2014). Business training and female enterprise start-up, growth, and dynamics: Experimental evidence from Sri Lanka. Journal of Development Economics, 106, 199-210.

[29] Di Leo, J. H. (1983). Interpreting Children's Drawings. New York: Routledge

[30] Duflo, E. (2012). Hope as capability. Tanner Lectures on Human Values and the Design of the Fight Against Poverty, 28-52.

[31] Duflo, E., and Saez, E. (2003). The role of information and social interactions in retirement plan decisions: Evidence from a randomized experiment. The Quarterly Journal of Economics, 118(3), 815-842.

[32] Duflo, E., Dupas, P., and Kremer, M. (2011). Peer effects, teacher incentives, and the impact of tracking: Evidence from a randomized evaluation in Kenya. American 
Economic Review, 101(5), 1739-74.

[33] Farokhi, M., and Hashemi, M. (2011). The Analysis of Children's Drawings: Social, Emotional, Physical, and Psychological Aspects. Procedia: Social and Behavioral Sciences 30(2011): 2219-24.

[34] Furth, G. M. (2002). The Secret World of Drawings: A Jungian Approach to Healing through Art. Toronto: Inner City Books.

[35] Garcia, A., Wydick, B., Cecchi, F., and Lensink, R. (2019). Aspirational Hope and Productivity: A Randomized Control Trial Among Dairy Farmers in Bolivia. AEA RCT Registry. August 30.

[36] Ghosal, S., Jana, S., Mani, A., Mitra, S. and Roy, S. (2020). Sex workers, Stigma and Self-Image: Evidence from Kolkata Brothels (No. 2020-03). Centre for the Study of African Economies, University of Oxford.

[37] Glewwe, P. W., Ilias, N., and Kremer, M. (2010). Teacher incentives. American Economic Journal: Applied Economics, pages 205227

[38] Glewwe, P., Ross, P. H., and Wydick, B. (2018). Developing Hope among Impoverished Children Using Child Self-Portraits to Measure Poverty Program Impacts. Journal of Human Resources, 53(2), 330-355.

[39] Guse, T., De Bruin, G. P., and Kok, M. (2016). Validation of the Childrens Hope Scale in a sample of South African adolescents. Child Indicators Research, 9(3), 757770.

[40] Heckman, J. J., and Kautz, T. (2012). Hard Evidence on Soft Skills. Labour Economics 19(4): 451-64.

[41] Heckman, J., Pinto, R. and Savelyev, P. (2013). Understanding the Mechanisms through Which an Influential Early Childhood Program Boosted Adult Outcomes. American Economic Review 103(6): 2052-86. 
[42] Heckman, J., Stixrud, J. and Urzua, S. (2006). The Effects of Cognitive and Noncognitive Abilities on Labor Market Outcomes and Social Behavior. Journal of Labor Economics 24(3): 41182.

[43] Jensen, R. and Oster, E. (2009). The Power of TV: Cable Television and Womens Status in India. The Quarterly Journal of Economics, 124(3):10571094.

[44] Klepsch, M., and Logie, L. (1982). Children Draw and Tell: An Introduction to the Projective Uses of Children's Human Figure Drawings. New York: Brunner/Maze.

[45] Kling, Jeffrey R., Jeffrey B. Liebman, and Lawrence F. Katz. (2007). Experimental Analysis of Neighborhood Effects. Econometrica 75(1): 83-119.

[46] Kliewer, W., and Lewis, H. (1995). Family influences on coping processes in children and adolescents with sickle cell disease. Journal of Pediatric Psychology, 20(4), $511-525$

[47] Koppitz, E. M. (1968). Psychological evaluation of children's human figure drawings. Grune and Stratton.

[48] Kremer, M., Brannen, C., and Glennerster, R. (2013). The challenge of education and learning in the developing world. Science (New York, N.Y.), 340(6130):297300.

[49] La Ferrara, E. (2019). Aspirations, Social Norms, and Development. Journal of the European Economic Association.

[50] La Ferrara, E., Chong, A., and Duryea, S. (2012). Soap operas and fertility: Evidence from Brazil. American Economic Journal: Applied Economics, 4(4), 1-31.

[51] Locke, E. A., and Latham, G. P. (1990). A Theory of Goal Setting and Task Performance. Englewood Cliffs, NJ: Prentice - Hall.

[52] Locke, E. and Latham, G. (2002). Building a Practically Useful Theory of Goal Setting and Task Motivation: A 35-Year Odyssey. American Psychologist 57 (9), 705717.

[53] Lockwood, P. (2006). "Someone like me can be successful": Do college students need same-gender role models? Psychology of Women Quarterly, 30(1):3646. 
[54] Lockwood, P. and Kunda, Z. (1997). Superstars and me: Predicting the impact of role models on the self. Journal of Personality and Social Psychology, 73(1):91103.

[55] Lybbert, T. and Wydick, B. (2016). Poverty, aspirations, and the economics of hope.

[56] Macours, K., and Vakis, R. (2014). Changing households' investment behaviour through social interactions with local leaders: Evidence from a randomised transfer programme. The Economic Journal, 124(576), 607-633.

[57] Magaletta, P. R., and Oliver, J. M. (1999). The hope construct, will, and ways: Their relations with self-efficacy, optimism, and general well-being. Journal of clinical psychology, 55(5), 539-551.

[58] McKelway, M. (2019). Experimental Evidence on the Effects of Women's Employment. Working Paper.

[59] McKenzie, D. (2012). Beyond baseline and follow-up: The case for more T in experiments. Journal of Development Economics, 99(2), 210-221.

[60] Miceli, M., and Castelfranchi, C. (2010). Hope: The power of wish and possibility. Theory and Psychology, 20(2), 251-276.

[61] Nguyen, T. (2008). Information, Role Models and Perceived Returns to Education: Experimental Evidence from Madagascar. MIT Job Market Paper.

[62] Osborne, J. W. (2015). What is rotating in exploratory factor analysis?. Practical Assessment, Research, and Evaluation, 20(1), 2.

[63] Peterson, L. W., and Hardin, M. E. (1997). Children in Distress: A Guide for Screening Children's Art. New York: W.W. Norton and Company.

[64] Pratham. (2014). Annual Status of Education Report (Rural) 2013. New Delhi, India: Pratham.

[65] Pulido-Martos, M., Jimnez-Moral, J. A., Lopez-Zafra, E., and Ruiz, J. R. (2014). An adaptation of the childrens hope scale in a sample of Spanish adolescents. Child Indicators Research, 7(2), 267-278. 
[66] Ray, D., (1998). Development Economics. Princeton, NJ: Princeton University Press. $[489,491,500]$

[67] Ray, D., (2006). Aspirations, poverty, and economic change. Understanding poverty. 409421.

[68] Riley, E. (2017). Increasing students' aspirations: the impact of Queen of Katwe on students' educational attainment. In CSAE Working Paper WPS/2017-13.

[69] Sachs, J. (2005). The End of Poverty: Economic Possibilities for Our Time. Penguin Press.

[70] Scheier, M. F., and Carver, C. S. (1985). Optimism, coping, and health: assessment and implications of generalized outcome expectancies. Health psychology, 4(3), 219.

[71] Sen, A. K. (1973). Behavior and the concept of preference. Economica. 40:24159

[72] Sen, A. (1999). Freedom as development.

[73] Snyder, C. R. (1994a). Hope and optimism. In V. S. Ramachandren (Ed.), Encyclopedia of human behavior (Vol. 2, pp. 535542). San Diego, CA: Academic.

[74] Snyder, C. R. (1994b). The psychology of hope: You can get there from here. New York: Free Press.

[75] Snyder, C. R. (Ed.). (2000). Handbook of hope: Theory, measures, and applications. Academic press.

[76] Snyder, C. R. (2002). Hope theory: Rainbows in the mind. Psychological inquiry, 13(4), 249-275.

[77] Snyder, C. R., Cheavens, J., and Sympson, S. C. (1997). Hope: An individual motive for social commerce. Group Dynamics: Theory, Research, and Practice, 1, 107118.

[78] Snyder, C. R., Harris, C., Anderson, J. R., Holleran, S. A., Irving, L. M., Sigmon, S. T. and Harney, P. (1991). The will and the ways: Development and validation of an 
individual-differences measure of hope. Journal of Personality and Social Psychology. 60(4), 570 .

[79] Snyder, C. R., Hoza, B., Pelham, W. E., Rapoff, M., Ware, L., Danovsky, M., Highberger, L., Ribinstein, H., and Stahl, K. J. (1997). The development and validation of the Children's Hope Scale. Journal of Pediatric Psychology, 22(3), 399-421.

[80] Snyder C., LaPointe A.B., Jeffrey Crowson J., and S. Early. (1998). Preferences of High-and Low Hope People for Self-Referential Input. Cognition and Emotion. 12: 807-823.

[81] Wadeson, H. B. A. (1971). Characteristics of Art Expression in Depression. Journal of Nervous and Mental Disease 153(3): 197-204.

[82] Walton, M. and Rao, V., (2004). Culture and public action. Stanford University Press.

[83] World Bank. (2003). World Development Report 2004: Making Services Work for Poor People. Washington, DC: World Bank.

[84] Wydick, B., Katz, E., Calvo, F., Gutierrez, F., and Janet, B. (2018). Shoeing the Children: the impact of the TOMS Shoe donation program in rural El Salvador. The World Bank Economic Review, 32(3), 727-751.

[85] Zizzo, D.J. (2010), Experimenter Demand Effects in Economic Experiments. Experimental Economics, 13(1): 75-98 
Figure 1: Theory of change

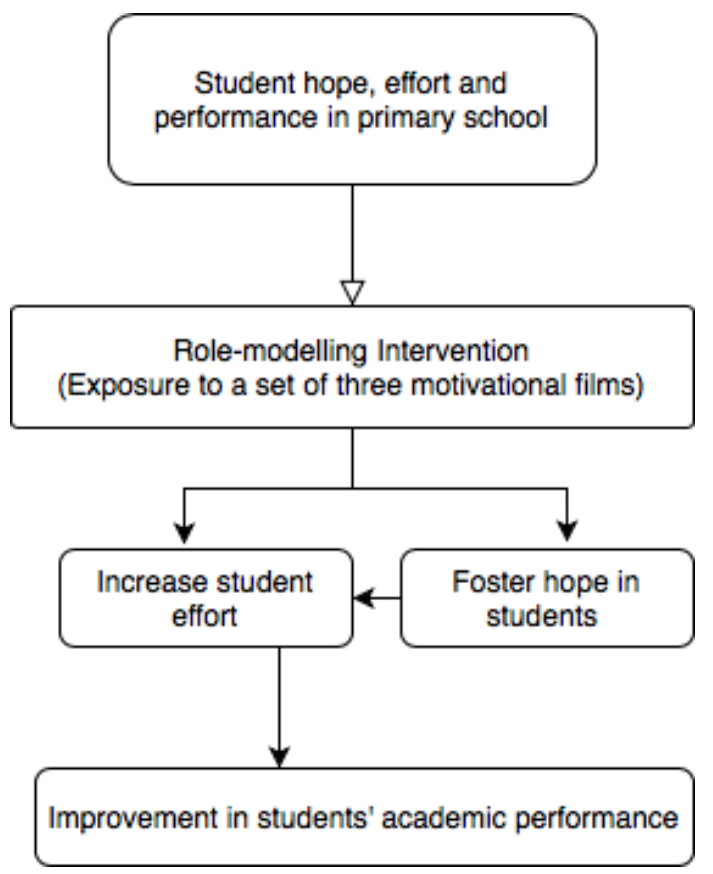

Figure 2: Timeline

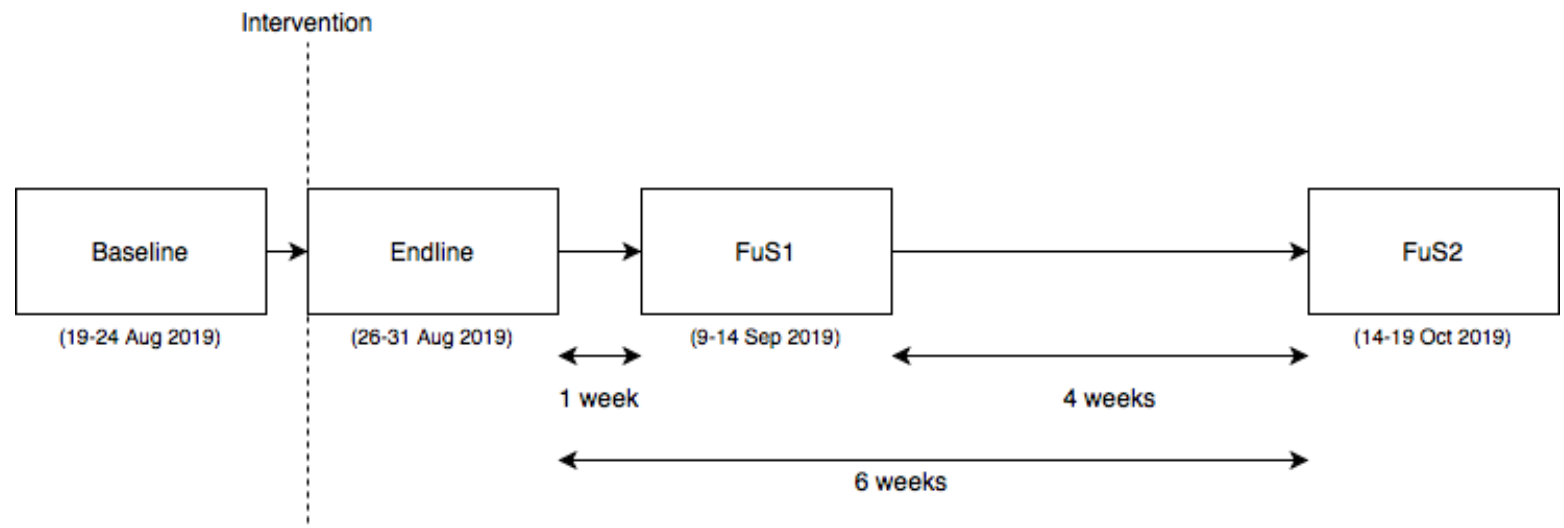


Figure 3

Panel (a): hope (before/after)

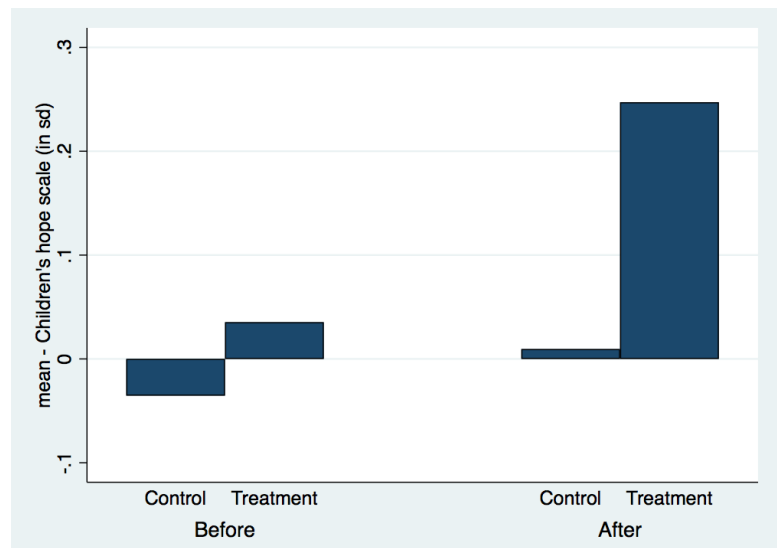

Panel (b): K-density - hope scores

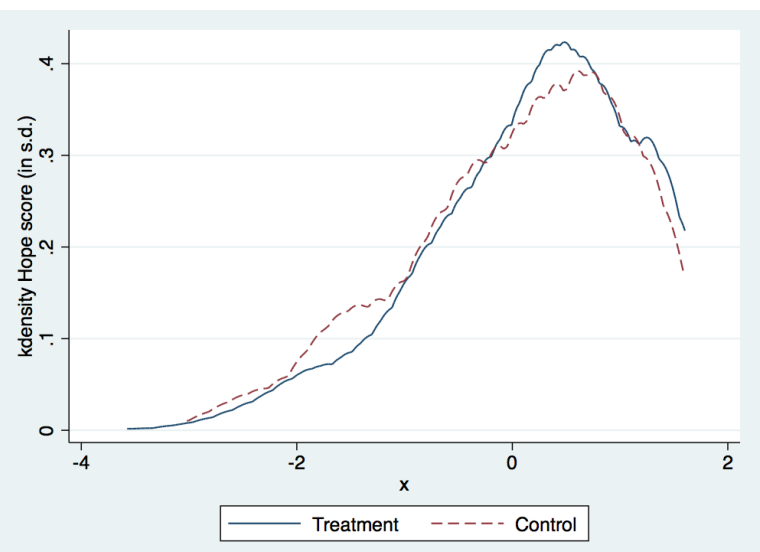

Notes: Panel (a) presents the treatment effect on hope scores (in s.d.) before and after the intervention. Panel (b) plots a histogram for hope scores by treatment assignment.

Table 1: Indicators - data collection strategy

\begin{tabular}{|c|c|c|c|}
\hline Outcome variable & Instrument & $\begin{array}{c}\text { Frequency } \\
\text { (time in minutes) }\end{array}$ & Explanation \\
\hline Hope & $\begin{array}{l}\text { Children's } \\
\text { Hope Scale }\end{array}$ & $\begin{array}{c}4 \\
(15-20)\end{array}$ & $\begin{array}{l}\text { A 6-item likert scale offering } \\
\text { a score between } 0-36\end{array}$ \\
\hline $\begin{array}{l}\text { SE/Optimism } \\
\text { and Happiness }\end{array}$ & Self-portraits & $\begin{array}{c}4 \\
(15)\end{array}$ & $\begin{array}{l}\text { Students are asked to draw } \\
\text { themselves on last Sunday }\end{array}$ \\
\hline Achievement & ASER test & $\begin{array}{c}4 \\
(25)\end{array}$ & $\begin{array}{l}\text { Standardised test for English } \\
\text { and Mathematics }(0-100)\end{array}$ \\
\hline Effort & $\begin{array}{l}\text { Substitution } \\
\text { Class (SC) }\end{array}$ & $\begin{array}{c}4 \\
(30-40)\end{array}$ & $\begin{array}{l}\text { Third party observations in a } \\
\text { free period scoring between } 0-3\end{array}$ \\
\hline Effort & $\begin{array}{l}\text { Remedial } \\
\text { Class (RC) }\end{array}$ & $\begin{array}{c}4 \\
(60)\end{array}$ & $\begin{array}{l}\text { Attendance in an optional after- } \\
\text { school remedial class }(0-1)\end{array}$ \\
\hline Achievement & Past performance & 1 & $\begin{array}{l}\text { Percentage scored in } \\
\text { class } 3 \text { examinations }\end{array}$ \\
\hline Covariates & $\begin{array}{c}\text { Survey } \\
\text { Questionnaires }\end{array}$ & $\begin{array}{c}1 \\
(15-20)\end{array}$ & $\begin{array}{l}\text { Information is collected from } \\
\text { students, teachers and parents }\end{array}$ \\
\hline
\end{tabular}


Table 2: Balancing checks

\begin{tabular}{|c|c|c|c|c|c|c|c|c|}
\hline \multirow[t]{2}{*}{ Variable } & \multirow[t]{2}{*}{ Label } & \multicolumn{2}{|c|}{$\mathrm{N}$} & \multicolumn{2}{|c|}{ Mean } & \multirow{2}{*}{$\begin{array}{c}\text { Difference } \\
\qquad \mathrm{C}-\mathrm{T}\end{array}$} & \multirow[t]{2}{*}{ T value } & \multirow[t]{2}{*}{ p-value } \\
\hline & & Control (C) & Treat (T) & $\mathrm{C}$ & $\mathrm{T}$ & & & \\
\hline \multicolumn{9}{|c|}{ Baseline data on covariates } \\
\hline Age & \# years & 226 & 226 & $\begin{array}{c}9.066 \\
(0.048)\end{array}$ & $\begin{array}{c}9.036 \\
(0.051)\end{array}$ & $\begin{array}{l}0.031 \\
(0.07)\end{array}$ & 0.45 & 0.658 \\
\hline Gender & 1 -male, 0 -female & 226 & 226 & $\begin{array}{c}0.633 \\
(0.032)\end{array}$ & $\begin{array}{c}0.589 \\
(0.033)\end{array}$ & $\begin{array}{c}0.044 \\
(0.046)\end{array}$ & 0.95 & 0.336 \\
\hline Private tuition & 1 - yes, 0 - no & 226 & 225 & $\begin{array}{c}0.438 \\
(0.033)\end{array}$ & $\begin{array}{c}0.449 \\
(0.033)\end{array}$ & $\begin{array}{l}-0.011 \\
(0.047)\end{array}$ & -0.25 & 0.818 \\
\hline Private tuition & \# hrs/week & 99 & 101 & $\begin{array}{l}11.101 \\
(4.255)\end{array}$ & $\begin{array}{l}10.916 \\
(3.878)\end{array}$ & $\begin{array}{c}0.185 \\
(0.576)\end{array}$ & 0.3 & 0.748 \\
\hline Religion & 1 - Hindu, $0-\mathrm{o} / \mathrm{w}$ & 226 & 225 & $\begin{array}{c}0.898 \\
(0.020)\end{array}$ & $\begin{array}{c}0.858 \\
(0.023)\end{array}$ & $\begin{array}{c}0.041 \\
(0.031)\end{array}$ & 1.3 & 0.19 \\
\hline Native & 1 - Jaipur, 0 - o/w & 226 & 225 & $\begin{array}{c}0.929 \\
(0.017)\end{array}$ & $\begin{array}{c}0.898 \\
(0.020)\end{array}$ & $\begin{array}{c}0.032 \\
(0.026)\end{array}$ & 1.2 & 0.236 \\
\hline Hh size & \# people & 225 & 224 & $\begin{array}{c}8.627 \\
(0.306)\end{array}$ & $\begin{array}{c}8.558 \\
(0.324)\end{array}$ & $\begin{array}{c}0.069 \\
(0.446)\end{array}$ & 0.15 & 0.878 \\
\hline Past perform & $\%$ in class 3 & 221 & 223 & $\begin{array}{c}77.93 \\
(1.045)\end{array}$ & $\begin{array}{l}76.781 \\
(0.975)\end{array}$ & $\begin{array}{c}1.149 \\
(1.429)\end{array}$ & 0.8 & 0.421 \\
\hline
\end{tabular}

Baseline data on indicators

\begin{tabular}{|c|c|c|c|c|c|c|c|c|}
\hline Hope score & CHS (0-36) & 222 & 222 & $\begin{array}{c}27.14 \\
(0.359)\end{array}$ & $\begin{array}{l}27.523 \\
(0.368)\end{array}$ & $\begin{array}{l}-0.383 \\
(0.513)\end{array}$ & -0.75 & 0.457 \\
\hline Effort & $\begin{array}{c}\text { SC }(0-3) \\
\text { Substitution class }\end{array}$ & 216 & 216 & $\begin{array}{c}1.11 \\
(0.071)\end{array}$ & $\begin{array}{l}1.106 \\
(0.074)\end{array}$ & $\begin{array}{c}0.004 \\
(0.103)\end{array}$ & 0.04 & 0.96 \\
\hline Achievement & ASER (0-100) & 216 & 216 & $\begin{array}{l}64.185 \\
(1.630)\end{array}$ & $\begin{array}{l}62.315 \\
(1.697)\end{array}$ & $\begin{array}{c}1.871 \\
(2.353)\end{array}$ & 0.8 & 0.427 \\
\hline
\end{tabular}

Baseline data from EFA on children's drawings

\begin{tabular}{|c|c|c|c|c|c|c|c|c|}
\hline SE/Optimism & $\begin{array}{c}\text { factor analysis } \\
\text { (EFA) }\end{array}$ & 207 & 207 & $\begin{array}{c}0.002 \\
(0.067)\end{array}$ & $\begin{array}{l}-0.114 \\
(0.080)\end{array}$ & $\begin{array}{c}0.116 \\
(0.105)\end{array}$ & 1.11 & 0.266 \\
\hline SE/Optimism & Kling's index & 207 & 207 & $\begin{array}{l}-0.735 \\
(0.019)\end{array}$ & $\begin{array}{l}-0.759 \\
(0.021)\end{array}$ & $\begin{array}{c}0.023 \\
(0.029)\end{array}$ & 0.81 & 0.417 \\
\hline
\end{tabular}

Notes: The sample contains primary school students surveyed at baseline $(\mathrm{N}=452)$. The $\mathrm{p}$-value corresponds to $\mathrm{p}$-values of the test under the null hypothesis of the equality of means between the treatment and placebo (here, control) groups.

Standard errors are reported in parenthesis with ${ }^{*}$ significant at 10 percent, ${ }^{* *}$ significant at 5 percent, and ${ }^{* * *}$ significant at 1 percent. 


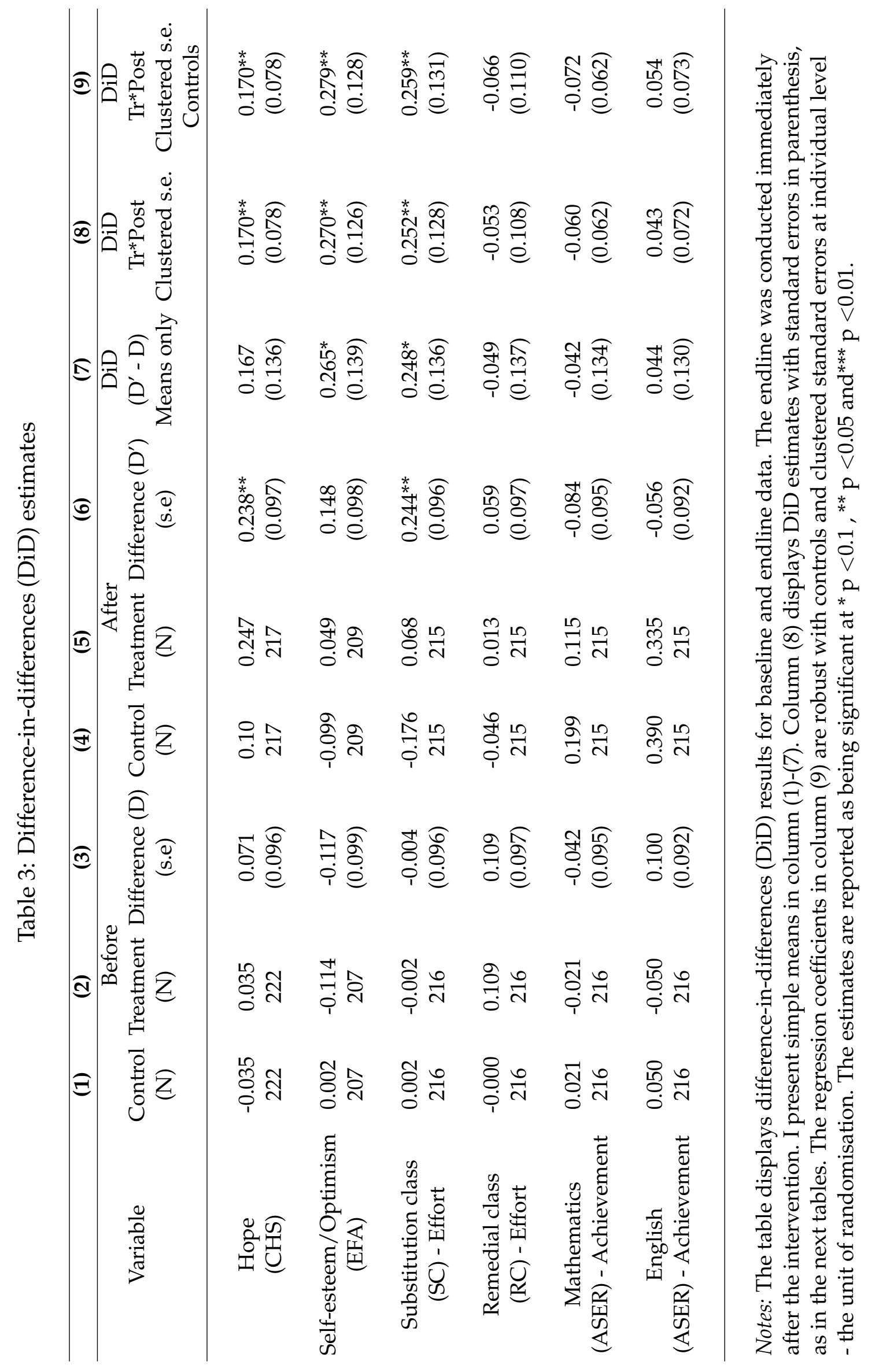


Table 4: Treatment effects - DiD

\begin{tabular}{|c|c|c|c|c|c|c|}
\hline \multirow{2}{*}{ Variable } & \multicolumn{2}{|c|}{ Before/After } & \multicolumn{2}{|c|}{1 week later } & \multicolumn{2}{|c|}{6 weeks later } \\
\hline & $(1)$ & (2) & (3) & (4) & (5) & (6) \\
\hline $\begin{array}{l}\text { Hope } \\
\text { (CHS) }\end{array}$ & $\begin{array}{l}0.170^{* *} \\
(0.078)\end{array}$ & $\begin{array}{l}0.170^{* *} \\
(0.078)\end{array}$ & $\begin{array}{l}-0.031 \\
(0.081)\end{array}$ & $\begin{array}{c}-0.042 \\
(0.083)\end{array}$ & $\begin{array}{c}0.024 \\
(0.090)\end{array}$ & $\begin{array}{c}0.028 \\
(0.092)\end{array}$ \\
\hline$N$ & 878 & 858 & 855 & 835 & 859 & 840 \\
\hline $\begin{array}{l}\text { SE/Optimism } \\
\text { (EFA) }\end{array}$ & $\begin{array}{l}0.270^{* *} \\
(0.126)\end{array}$ & $\begin{array}{l}0.279^{* *} \\
(0.128)\end{array}$ & $\begin{array}{l}0.225^{*} \\
(0.126)\end{array}$ & $\begin{array}{l}0.237^{*} \\
(0.128)\end{array}$ & $\begin{array}{l}0.313^{* *} \\
(0.131)\end{array}$ & $\begin{array}{c}0.340^{* * *} \\
(0.133)\end{array}$ \\
\hline$N$ & 832 & 814 & 824 & 808 & 825 & 810 \\
\hline $\begin{array}{l}\text { Effort } \\
(\mathrm{SC})\end{array}$ & $\begin{array}{l}0.252^{* *} \\
(0.128)\end{array}$ & $\begin{array}{l}0.259^{* *} \\
(0.131)\end{array}$ & $\begin{array}{l}-0.053 \\
(0.131)\end{array}$ & $\begin{array}{c}-0.071 \\
(0.133)\end{array}$ & $\begin{array}{l}-0.046 \\
(0.138)\end{array}$ & $\begin{array}{l}-0.040 \\
(0.139)\end{array}$ \\
\hline $\begin{array}{l}\text { Effort } \\
(\mathrm{RC})\end{array}$ & $\begin{array}{l}-0.053 \\
(0.108)\end{array}$ & $\begin{array}{l}-0.066 \\
(0.110)\end{array}$ & $\begin{array}{l}-0.063 \\
(0.105)\end{array}$ & $\begin{array}{l}-0.044 \\
(0.106)\end{array}$ & $\begin{array}{c}0.069 \\
(0.107)\end{array}$ & $\begin{array}{c}0.056 \\
(0.109)\end{array}$ \\
\hline $\begin{array}{l}\text { Achievement } \\
\text { (Mathematics) }\end{array}$ & $\begin{array}{l}-0.060 \\
(0.062)\end{array}$ & $\begin{array}{c}-0.072 \\
(0.062)\end{array}$ & $\begin{array}{c}0.067 \\
(0.069)\end{array}$ & $\begin{array}{c}0.073 \\
(0.069)\end{array}$ & $\begin{array}{c}0.008 \\
(0.076)\end{array}$ & $\begin{array}{l}-0.014 \\
(0.077)\end{array}$ \\
\hline $\begin{array}{c}\text { Achievement } \\
\text { (English) }\end{array}$ & $\begin{array}{c}0.043 \\
(0.072)\end{array}$ & $\begin{array}{c}0.054 \\
(0.073)\end{array}$ & $\begin{array}{c}0.092 \\
(0.732)\end{array}$ & $\begin{array}{l}0.119^{*} \\
(0.073)\end{array}$ & $\begin{array}{l}0.158^{* *} \\
(0.071)\end{array}$ & $\begin{array}{l}0.160^{* *} \\
(0.072)\end{array}$ \\
\hline$N$ & 862 & 843 & 843 & 824 & 847 & 829 \\
\hline Controls & No & Yes & No & Yes & No & Yes \\
\hline
\end{tabular}

Notes: The table displays difference-in-differences (DiD) results for the entire study, including 4 data collection rounds. Robust standard errors clustered at individual level are reported in parenthesis. Estimates are reported as being significant at ${ }^{*} \mathrm{p}<0.1$, ${ }^{* *} \mathrm{p}<0.05$ and ${ }^{* *} \mathrm{p}<0.01$. 
Table 5: Treatment effects - Ancova

\begin{tabular}{|c|c|c|c|c|c|}
\hline Variable & $\begin{array}{c}(1) \\
\text { Before/After }\end{array}$ & $\begin{array}{c}(2) \\
1 \text { week later }\end{array}$ & $\begin{array}{c}\text { (3) } \\
6 \text { weeks later }\end{array}$ & $\begin{array}{c}\text { (4) } \\
\text { Overall effect }\end{array}$ & $\begin{array}{c}\text { (5) } \\
\text { Overall effect }\end{array}$ \\
\hline Hope & $\begin{array}{c}0.191^{* * *} \\
(0.072)\end{array}$ & $\begin{array}{l}-0.004 \\
(0.073)\end{array}$ & $\begin{array}{c}0.051 \\
(0.082)\end{array}$ & $\begin{array}{c}0.019 \\
(0.043)\end{array}$ & $\begin{array}{c}0.027 \\
(0.043)\end{array}$ \\
\hline$N$ & 430 & 405 & 409 & 1189 & 1168 \\
\hline SE/optimism & $\begin{array}{c}0.152^{* * *} \\
(0.040)\end{array}$ & $\begin{array}{c}0.115 \\
(0.095)\end{array}$ & $\begin{array}{l}0.216^{* *} \\
(0.083)\end{array}$ & $\begin{array}{c}0.147^{* * *} \\
(0.044)\end{array}$ & $\begin{array}{c}0.146^{* * *} \\
(0.044)\end{array}$ \\
\hline$N$ & 387 & 380 & 381 & 1148 & 1129 \\
\hline $\begin{array}{l}\text { Effort } \\
\text { (SC) }\end{array}$ & $\begin{array}{c}0.268^{* * *} \\
(0.097)\end{array}$ & $\begin{array}{l}-0.077 \\
(0.106)\end{array}$ & $\begin{array}{l}-0.035 \\
(0.106)\end{array}$ & $\begin{array}{l}-0.035 \\
(0.062)\end{array}$ & $\begin{array}{l}-0.0306 \\
(0.062)\end{array}$ \\
\hline $\begin{array}{l}\text { Effort } \\
\text { (RC) }\end{array}$ & $\begin{array}{c}0.009 \\
(0.090)\end{array}$ & $\begin{array}{c}0.003 \\
(0.084)\end{array}$ & $\begin{array}{c}0.129 \\
(0.086)\end{array}$ & $\begin{array}{c}0.162^{* * *} \\
(0.049)\end{array}$ & $\begin{array}{c}0.175^{* * *} \\
(0.050)\end{array}$ \\
\hline Math & $\begin{array}{l}-0.072 \\
(0.058)\end{array}$ & $\begin{array}{c}0.052 \\
(0.063)\end{array}$ & $\begin{array}{l}-0.016 \\
(0.068)\end{array}$ & $\begin{array}{c}0.002 \\
(0.037)\end{array}$ & $\begin{array}{l}0.0176 \\
(0.036)\end{array}$ \\
\hline English & $\begin{array}{c}0.006 \\
(0.063)\end{array}$ & $\begin{array}{c}0.046 \\
(0.060)\end{array}$ & $\begin{array}{l}0.102^{*} \\
(0.053)\end{array}$ & $\begin{array}{c}0.093^{* * *} \\
(0.027)\end{array}$ & $\begin{array}{c}0.110^{* * *} \\
(0.027)\end{array}$ \\
\hline$N$ & 414 & 396 & 399 & 1176 & 1155 \\
\hline Controls & Yes & Yes & Yes & No & Yes \\
\hline
\end{tabular}

Notes: The table displays the treatment effects using ANCOVA that controls for baseline values of the outcome variables. Column (1)-(3) present estimates for each wave. Column (4) and (5) present the overall average treatment effects using a pooled sample. This pooled sample results in higher power to detect an overall effect. Standard errors are in parenthesis. The estimates are reported as being significant at ${ }^{*} p<0.1,{ }^{* *} p<0.05$ and ${ }^{* * *} \mathrm{p}<0.01$. 
Table 6: DiD estimates for self-portraits

\begin{tabular}{ccccccc}
\hline Variable & \multicolumn{2}{c}{$\begin{array}{c}\text { Before/After } \\
(1)\end{array}$} & \multicolumn{2}{c}{ After 1 week } & \multicolumn{2}{c}{ After 6 weeks } \\
& & $(3)$ & $(4)$ & $(5)$ & $(6)$ \\
\hline SE/Optimism & $0.270^{* *}$ & $0.279^{* *}$ & $0.225^{*}$ & $0.237^{*}$ & $0.313^{* *}$ & $0.340^{* * *}$ \\
Factor Analysis & $(0.126)$ & $(0.128)$ & $(0.126)$ & $(0.128)$ & $(0.131)$ & $(0.133)$ \\
& & & & & & \\
SE/Optimism & $0.055^{* *}$ & $0.055^{* *}$ & $0.052^{* *}$ & $0.053^{* *}$ & $0.066^{* *}$ & $0.068^{* * *}$ \\
Kling's index & $(0.025)$ & $(0.025)$ & $(0.025)$ & $(0.025)$ & $(0.026)$ & $(0.027)$ \\
SE/Optimism & $0.048^{* *}$ & $0.046^{* *}$ & 0.035 & $0.039^{*}$ & $0.053^{* *}$ & $0.059^{* * *}$ \\
Anderson's index & $(0.023)$ & $(0.23)$ & $(0.022)$ & $(0.023)$ & $(0.022)$ & $(0.022)$ \\
& & & & & & \\
Happiness & 0.176 & 0.173 & $0.197^{*}$ & $0.202^{*}$ & $0.184^{*}$ & $0.199^{*}$ \\
Factor Analysis & $(0.138)$ & $(0.140)$ & $(0.116)$ & $(0.118)$ & $(0.105)$ & $(0.107)$ \\
\hline $\mathrm{N}$ & & & & & & \\
\hline Controls & 832 & 814 & 824 & 808 & 825 & 810 \\
\hline
\end{tabular}

Notes: DiD estimates for the indices created from children's drawings. See section 3.3.1 and 5.2.2 for details. Standard errors, in parenthesis, are clustered at individual level. Estimates are reported as being significant at ${ }^{*} \mathrm{p}<0.1,{ }^{* *} \mathrm{p}<0.05$ and ${ }^{* * *} \mathrm{p}<0.01$. 
Table 7: Heterogeneous effects by gender, age and past performance

Panel (a): Psychological outcomes

\begin{tabular}{|c|c|c|c|c|c|c|c|c|c|}
\hline & $\begin{array}{l}\text { (1) } \\
\text { Hope }\end{array}$ & $\begin{array}{l}\text { (2) } \\
\text { Hope }\end{array}$ & $\begin{array}{l}(3) \\
\text { Hope }\end{array}$ & $\begin{array}{c}(4) \\
\text { SE/Optimism }\end{array}$ & $\begin{array}{c}\text { (5) } \\
\text { SE/Optimism }\end{array}$ & $\begin{array}{c}\text { (6) } \\
\text { SE/Optimism }\end{array}$ & $\begin{array}{c}(7) \\
\text { Happiness }\end{array}$ & $\begin{array}{c}(8) \\
\text { Happiness }\end{array}$ & $\begin{array}{c}9) \\
\text { Happiness }\end{array}$ \\
\hline Treatment & $\begin{array}{l}0.170^{* *} \\
(0.078)\end{array}$ & $\begin{array}{l}0.171^{* *} \\
(0.078)\end{array}$ & $\begin{array}{l}0.171^{* *} \\
(0.078)\end{array}$ & $\begin{array}{l}0.278^{* *} \\
(0.126)\end{array}$ & $\begin{array}{l}0.279^{* *} \\
(0.126)\end{array}$ & $\begin{array}{l}0.283^{* *} \\
(0.126)\end{array}$ & $\begin{array}{c}0.176 \\
(0.137)\end{array}$ & $\begin{array}{c}0.176 \\
(0.138)\end{array}$ & $\begin{array}{c}0.176 \\
(0.137)\end{array}$ \\
\hline Male & $\begin{array}{c}0.142 \\
(0.135)\end{array}$ & $\begin{array}{c}0.121 \\
(0.091)\end{array}$ & $\begin{array}{c}0.118 \\
(0.091)\end{array}$ & $\begin{array}{c}-0.381^{* * * *} \\
(0.094)\end{array}$ & $\begin{array}{c}-0.318^{* * *} \\
(0.068)\end{array}$ & $\begin{array}{c}-0.308^{* * * *} \\
(0.068)\end{array}$ & $\begin{array}{c}0.043 \\
(0.091)\end{array}$ & $\begin{array}{c}0.057 \\
(0.074)\end{array}$ & $\begin{array}{c}0.054 \\
(0.073)\end{array}$ \\
\hline Above median age & $\begin{array}{c}0.037 \\
(0.108)\end{array}$ & $\begin{array}{l}-0.037 \\
(0.160)\end{array}$ & $\begin{array}{c}0.033 \\
(0.108)\end{array}$ & $\begin{array}{c}0.060 \\
(0.096)\end{array}$ & $\begin{array}{l}0.302^{* * *} \\
(0.112)\end{array}$ & $\begin{array}{c}0.051 \\
(0.095)\end{array}$ & $\begin{array}{l}-0.077 \\
(0.088)\end{array}$ & $\begin{array}{l}-0.130 \\
(0.116)\end{array}$ & $\begin{array}{l}-0.081 \\
(0.088)\end{array}$ \\
\hline $\begin{array}{l}\text { Above median baseline } \\
\text { exam record }\end{array}$ & $\begin{array}{l}0.215^{* *} \\
(0.087)\end{array}$ & $\begin{array}{l}0.218^{* *} \\
(0.087)\end{array}$ & $\begin{array}{l}0.321^{* *} \\
(0.129)\end{array}$ & $\begin{array}{c}0.015 \\
(0.075)\end{array}$ & $\begin{array}{c}0.003 \\
(0.074)\end{array}$ & $\begin{array}{c}0.089 \\
(0.108)\end{array}$ & $\begin{array}{l}-0.099 \\
(0.070)\end{array}$ & $\begin{array}{l}-0.097 \\
(0.070)\end{array}$ & $\begin{array}{l}-0.056 \\
(0.081)\end{array}$ \\
\hline Tr*male & $\begin{array}{l}-0.047 \\
(0.183)\end{array}$ & & & $\begin{array}{c}0.146 \\
(0.136)\end{array}$ & & & $\begin{array}{c}0.023 \\
(0.140)\end{array}$ & & \\
\hline Tr*age & & $\begin{array}{c}0.151 \\
(0.215)\end{array}$ & & & $\begin{array}{c}-0.490^{* * *} \\
(0.183)\end{array}$ & & & $\begin{array}{c}0.103 \\
(0.172)\end{array}$ & \\
\hline Tr*baseline exam & & & $\begin{array}{l}-0.214 \\
(0.174)\end{array}$ & & & $\begin{array}{l}-0.151 \\
(0.148)\end{array}$ & & & $\begin{array}{l}-0.086 \\
(0.146)\end{array}$ \\
\hline Constant & $\begin{array}{l}-0.249^{* *} \\
(0.117)\end{array}$ & $\begin{array}{c}-0.220^{* *} \\
(0.103)\end{array}$ & $\begin{array}{c}-0.289^{* *} \\
(0.112)\end{array}$ & $\begin{array}{c}0.215^{* * *} \\
(0.071)\end{array}$ & $\begin{array}{c}0.125 \\
(0.082)\end{array}$ & $\begin{array}{c}0.132 \\
(0.088)\end{array}$ & $\begin{array}{c}0.069 \\
(0.099)\end{array}$ & $\begin{array}{c}0.071 \\
(0.081)\end{array}$ & $\begin{array}{c}0.041 \\
(0.093)\end{array}$ \\
\hline $\mathrm{N}$ & 878 & 878 & 878 & 832 & 832 & 832 & 832 & 832 & 832 \\
\hline
\end{tabular}

Panel (b): Effort and Achievement

\begin{tabular}{|c|c|c|c|c|c|c|c|c|c|c|c|c|}
\hline & $\begin{array}{l}\text { (1) } \\
\text { SC }\end{array}$ & $\begin{array}{l}\text { (2) } \\
\text { SC }\end{array}$ & $\begin{array}{l}\text { (3) } \\
\text { SC }\end{array}$ & $\begin{array}{l}\text { (4) } \\
\mathrm{RC}\end{array}$ & $\begin{array}{l}\text { (5) } \\
\mathrm{RC}\end{array}$ & $\begin{array}{l}\text { (6) } \\
\text { RC }\end{array}$ & $\begin{array}{c}\text { (7) } \\
\text { English }\end{array}$ & $\begin{array}{c}\text { (8) } \\
\text { English }\end{array}$ & $\begin{array}{c}(9) \\
\text { English }\end{array}$ & $\begin{array}{c}\text { (10) } \\
\text { Math }\end{array}$ & $\begin{array}{c}\text { (11) } \\
\text { Math }\end{array}$ & $\begin{array}{c}\text { (12) } \\
\text { Math }\end{array}$ \\
\hline Treatment & $\begin{array}{l}0.261^{* *} \\
(0.128)\end{array}$ & $\begin{array}{l}0.261^{* *} \\
(0.129)\end{array}$ & $\begin{array}{l}0.262^{* *} \\
(0.128)\end{array}$ & $\begin{array}{c}-0.051 \\
(0.109)\end{array}$ & $\begin{array}{c}-0.052 \\
(0.109)\end{array}$ & $\begin{array}{c}-0.053 \\
(0.109)\end{array}$ & $\begin{array}{l}-0.053 \\
(0.062)\end{array}$ & $\begin{array}{l}-0.053 \\
(0.062)\end{array}$ & $\begin{array}{c}-0.054 \\
(0.062)\end{array}$ & $\begin{array}{c}0.053 \\
(0.072)\end{array}$ & $\begin{array}{c}0.053 \\
(0.072)\end{array}$ & $\begin{array}{c}0.053 \\
(0.072)\end{array}$ \\
\hline Male & $\begin{array}{c}-0.195^{*} \\
(0.104)\end{array}$ & $\begin{array}{l}-0.178^{* *} \\
(0.0747)\end{array}$ & $\begin{array}{l}-0.177^{* *} \\
(0.0744)\end{array}$ & $\begin{array}{l}-0.135 \\
(0.119)\end{array}$ & $\begin{array}{l}-0.056 \\
(0.085)\end{array}$ & $\begin{array}{l}-0.053 \\
(0.084)\end{array}$ & $\begin{array}{c}-0.008 \\
(0.110)\end{array}$ & $\begin{array}{c}0.071 \\
(0.079)\end{array}$ & $\begin{array}{c}0.070 \\
(0.079)\end{array}$ & $\begin{array}{c}-0.238^{* *} \\
(0.106)\end{array}$ & $\begin{array}{c}-0.193^{* *} \\
(0.076)\end{array}$ & $\begin{array}{c}-0.194^{* *} \\
(0.076)\end{array}$ \\
\hline Above median age & $\begin{array}{l}-0.104 \\
(0.083)\end{array}$ & $\begin{array}{l}-0.073 \\
(0.114)\end{array}$ & $\begin{array}{l}-0.108 \\
(0.083)\end{array}$ & $\begin{array}{c}-0.026 \\
(0.095)\end{array}$ & $\begin{array}{c}0.018 \\
(0.130)\end{array}$ & $\begin{array}{l}-0.023 \\
(0.094)\end{array}$ & $\begin{array}{c}-0.376^{* * *} \\
(0.098)\end{array}$ & $\begin{array}{c}-0.407^{* * *} \\
(0.148)\end{array}$ & $\begin{array}{c}-0.379 * * * \\
(0.098)\end{array}$ & $\begin{array}{c}-0.371^{* * *} \\
(0.097)\end{array}$ & $\begin{array}{c}-0.392^{* * *} \\
(0.135)\end{array}$ & $\begin{array}{c}-0.373^{* * *} \\
(0.097)\end{array}$ \\
\hline $\begin{array}{l}\text { Above median baseline } \\
\text { Exam performance }\end{array}$ & $\begin{array}{c}0.109 \\
(0.070)\end{array}$ & $\begin{array}{c}0.108 \\
(0.071)\end{array}$ & $\begin{array}{l}0.174^{*} \\
(0.096)\end{array}$ & $\begin{array}{c}0.050 \\
(0.081)\end{array}$ & $\begin{array}{c}0.047 \\
(0.081)\end{array}$ & $\begin{array}{l}-0.096 \\
(0.110)\end{array}$ & $\begin{array}{l}0.806^{* * *} \\
(0.078)\end{array}$ & $\begin{array}{l}0.806^{* * *} \\
(0.079)\end{array}$ & $\begin{array}{l}0.774^{* * *} \\
(0.108)\end{array}$ & $\begin{array}{l}0.642^{* * *} \\
(0.077)\end{array}$ & $\begin{array}{l}0.642^{* * *} \\
(0.078)\end{array}$ & $\begin{array}{l}0.629 * * * \\
(0.108)\end{array}$ \\
\hline Tr*male & $\begin{array}{c}0.035 \\
(0.149)\end{array}$ & & & $\begin{array}{c}0.158 \\
(0.167)\end{array}$ & & & $\begin{array}{c}0.152 \\
(0.158)\end{array}$ & & & $\begin{array}{c}0.085 \\
(0.151)\end{array}$ & & \\
\hline Tr*age & & $\begin{array}{l}-0.062 \\
(0.167)\end{array}$ & & & $\begin{array}{l}-0.097 \\
(0.186)\end{array}$ & & & $\begin{array}{c}0.054 \\
(0.197)\end{array}$ & & & $\begin{array}{c}0.038 \\
(0.191)\end{array}$ & \\
\hline $\mathrm{Tr}^{*}$ baseline exam & & & $\begin{array}{l}-0.131 \\
(0.142)\end{array}$ & & & $\begin{array}{l}0.291^{*} \\
(0.161)\end{array}$ & & & $\begin{array}{c}0.062 \\
(0.158)\end{array}$ & & & $\begin{array}{c}0.025 \\
(0.154)\end{array}$ \\
\hline Constant & $\begin{array}{c}0.097 \\
(0.099)\end{array}$ & $\begin{array}{c}0.080 \\
(0.088)\end{array}$ & $\begin{array}{c}0.053 \\
(0.091)\end{array}$ & $\begin{array}{c}0.068 \\
(0.111)\end{array}$ & $\begin{array}{c}0.008 \\
(0.098)\end{array}$ & $\begin{array}{c}0.092 \\
(0.104)\end{array}$ & $\begin{array}{l}-0.315^{* * *} \\
(0.099)\end{array}$ & $\begin{array}{l}-0.358^{* * * *} \\
(0.090)\end{array}$ & $\begin{array}{c}-0.347^{* * * *} \\
(0.100)\end{array}$ & $\begin{array}{l}-0.053 \\
(0.098)\end{array}$ & $\begin{array}{l}-0.076 \\
(0.091)\end{array}$ & $\begin{array}{c}-0.074 \\
(0.102)\end{array}$ \\
\hline $\mathrm{N}$ & 862 & 862 & 862 & 862 & 862 & 862 & 862 & 862 & 862 & 862 & 862 & 862 \\
\hline
\end{tabular}

Notes: Treatment effects on a host of dependent variables as in columns (1)-(9) in panel (a) and columns (1)-(12) in panel (b) are presented. In panel (a) column (1), (4) and (7) show the heterogeneous effect from gender. Similar effects on gender in panel (b) are in column (1), (4), (7) and (10). The effect of age in panel (a) is captured in columns (2), (5) and (8). Similarly, for panel (b) the effect of age is in columns (2), (5), (8) and (11). Columns (3), (6), and (9) capture the heterogeneous effects on the basis of past performance in panel (a). Similar effects on effort and achievement are in columns (3), (6), (9) and (12). See section 5.3 for more details. Standard errors, in parenthesis, are clustered at individual level. The estimates are reported as being significant at ${ }^{*} \mathrm{p}<0.1,{ }^{* *} \mathrm{p}<0.05$ and ${ }^{* * *} \mathrm{p}<0.01$. Confounding factors are controlled for in all the estimates. 
Table 8: Heterogeneous effects on optimism by age and gender

\begin{tabular}{lcc}
\hline & $(1)$ & $(2)$ \\
& SE/Optimism & SE/Optimism \\
\hline Treatment & $0.287^{* *}$ & $0.282^{* *}$ \\
& $(0.126)$ & $(0.126)$ \\
Above median age & 0.112 & 0.134 \\
& $(0.101)$ & $(0.111)$ \\
Male & $-0.286^{* * *}$ & \\
& $(0.067)$ & \\
Female & & $0.357^{* * *}$ \\
& & $(0.069)$ \\
tr*(above median age ${ }^{*}$ male) & -0.201 & \\
tr*(above median age ${ }^{*}$ female) & $(0.221)$ & $-0.422^{*}$ \\
& & $(0.228)$ \\
Constant & & $-0.237^{*}$ \\
& 0.095 & $(0.121)$ \\
\hline R-square & $(0.107)$ & 0.034 \\
Observations & 0.031 & 829 \\
\hline
\end{tabular}

Notes: Treatment effects on self-efficacy or optimism by age and gender are presented in the former table. An interaction between gender and above median age is presented in this table. See section 5.3 for details. Standard errors are clustered at individual level. The estimates include controls and are reported as being significant at ${ }^{*} \mathrm{p}<0.1,{ }^{* *} \mathrm{p}<0.05$ and ${ }^{* * *} \mathrm{p}<0.01$. 
Table 9: Heterogeneous effects by hope quantiles

\begin{tabular}{lcccccc}
\hline & $(1)$ & $(2)$ & $(3)$ & $(4)$ & $(5)$ & $(6)$ \\
& Hope & SE/Optimism & Effort (sc) & Effort (rc) & Math & English \\
\hline treatment & $0.174^{* *}$ & $0.299^{* *}$ & $0.270^{* *}$ & -0.054 & -0.064 & 0.055 \\
& $(0.078)$ & $(0.126)$ & $(0.129)$ & $(0.109)$ & $(0.061)$ & $(0.072)$ \\
tr* quintile 1 & $0.232^{*}$ & -0.184 & -0.138 & -0.093 & 0.015 & 0.129 \\
& $(0.137)$ & $(0.183)$ & $(0.159)$ & $(0.175)$ & $(0.185)$ & $(0.186)$ \\
$t^{*}$ quintile 2 & -0.224 & 0.180 & 0.158 & $0.360 *$ & $0.311^{*}$ & $0.275 *$ \\
& $(0.140)$ & $(0.193)$ & $(0.154)$ & $(0.188)$ & $(0.172)$ & $(0.165)$ \\
$t^{*}$ quintile 3 & -0.150 & 0.030 & $0.281^{*}$ & -0.102 & -0.133 & -0.100 \\
& $(0.137)$ & $(0.150)$ & $(0.168)$ & $(0.181)$ & $(0.177)$ & $(0.171)$ \\
$t^{*}$ quintile 4 & -0.099 & -0.065 & $-0.319^{*}$ & -0.256 & $-0.309 *$ & $-0.341^{* *}$ \\
& $(0.118)$ & $(0.160)$ & $(0.176)$ & $(0.188)$ & $(0.164)$ & $(0.163)$ \\
\hline Observations & 874 & 829 & 858 & 858 & 858 & 858 \\
R-squared & 0.44 & 0.031 & 0.033 & 0.026 & 0.237 & 0.217 \\
\hline
\end{tabular}

Notes: Treatment effects on the dependent variables in column (1)-(6) by baseline hope scores. These scores are split by quantiles. Standard errors, in parenthesis, are clustered at individual level and reported as being significant at ${ }^{*} p<0.1,{ }^{* *} p<0.05$ and ${ }^{* * *}$ $\mathrm{p}<0.01$. Confounding factors are controlled for in all the estimates. 


\section{Appendix}

\subsection{Proof of Proposition 1}

Agent solves the following maximization problem:

$$
\max _{e} U(e, \delta)=p(e, \delta)[\bar{\theta}-\underline{\theta}]+\underline{\theta}-c(e)
$$

Consider a solution point for this maximization problem $\left(e^{*}, \delta^{*}\right)$. At this point,

$$
\frac{\partial U(e, \delta)}{\partial e}=0
$$

from the necessary first order condition. That is,

$$
\frac{\partial p(e, \delta)}{\partial e}[\bar{\theta}-\underline{\theta}]-\frac{\partial c(e)}{\partial e}=0
$$

Then, by applying the Implicit Function Theorem, we have

$$
\frac{\partial e}{\partial \delta}=-\frac{\partial^{2} p(e, \delta)}{\partial e \partial \delta} / \frac{\partial^{2} p(e, \delta)}{\partial e^{2}}
$$

Moreover, at $\left(e^{*}, \delta^{*}\right)$, by the sufficient condition of the maximization problem, we have:

$$
\frac{\partial^{2} p(e, \delta)}{\partial e^{2}}<0
$$

Also, by assumption 3:

$$
\frac{\partial^{2} p(e, \delta)}{\partial e \partial \delta}>0
$$

Hence,

$$
\frac{\partial e}{\partial \delta}=-\frac{\partial^{2} p(e, \delta)}{\partial e \partial \delta} / \frac{\partial^{2} p(e, \delta)}{\partial e^{2}}>0
$$




\subsection{Tables}

Table 10: A.1 Sample composition

\begin{tabular}{|c|c|c|c|c|c|c|c|c|c|c|c|}
\hline \multicolumn{12}{|c|}{ School identification criteria } \\
\hline School & \# Boys & \# Girls & Total & \# Teachers & $>3 \mathrm{kms}$ apart & $<8 \mathrm{kms}$ apart & Class 0-12 & CBSE & Private & Tarined teachers & $>40$ students \\
\hline 1 & 23 & 18 & 41 & 11 & $\checkmark$ & $\checkmark$ & $\checkmark$ & $\checkmark$ & $\checkmark$ & $\checkmark$ & $\checkmark$ \\
\hline 2 & 57 & 37 & 94 & 10 & $\checkmark$ & $\checkmark$ & $\checkmark$ & $\checkmark$ & $\checkmark$ & $\checkmark$ & $\checkmark$ \\
\hline 3 & 54 & 24 & 78 & 5 & $\checkmark$ & $\checkmark$ & $\checkmark$ & $\checkmark$ & $\checkmark$ & $\checkmark$ & $\checkmark$ \\
\hline 4 & 54 & 37 & 91 & 5 & $\checkmark$ & $\checkmark$ & $\checkmark$ & $\checkmark$ & $\checkmark$ & $\checkmark$ & $\checkmark$ \\
\hline 5 & 57 & 46 & 103 & 9 & $\checkmark$ & $\checkmark$ & $\checkmark$ & $\checkmark$ & $\checkmark$ & $\checkmark$ & $\checkmark$ \\
\hline 6 & 31 & 14 & 45 & 6 & $\checkmark$ & $\checkmark$ & $\checkmark$ & $\checkmark$ & $\checkmark$ & $\checkmark$ & $\checkmark$ \\
\hline
\end{tabular}

Table 11: A.2 Summary statistics

\begin{tabular}{cccccccc}
\hline Variable & Label & N & Mean & sd & Min & Max & Median \\
\hline Age & \# years & 452 & 9.05 & 0.74 & 7 & 12 & 9 \\
Gender & 0 - female, 1 - male & 452 & 0.61 & 0.49 & 0 & 1 & 1 \\
\%ast performance & \% in class 3 & 444 & 77.35 & 15.04 & 34.40 & 98.80 & 80.25 \\
Private tuition & 1 - yes, 0 - otherwise & 451 & 0.44 & 0.50 & 0 & 1 & 0 \\
Tuition hours & \# hours / week & 200 & 11.01 & 4.06 & 3 & 28 & 12 \\
Religion & 1 - Hindu, 0 - otherwise & 451 & 0.88 & 0.33 & 0 & 1 & 1 \\
Native & 1 - yes, 0 - otherwise & 451 & 0.91 & 0.28 & 0 & 1 & 1 \\
Household size & \# people & 449 & 8.59 & 4.71 & 2 & 30 & 8 \\
Study time & \# hours / week & 451 & 6.48 & 4.46 & 0 & 28 & 7 \\
Best friend in class & 1 - yes, 0 - otherwise & 451 & 0.75 & 0.44 & 0 & 1 & 1 \\
July attendance & \#days attended/ open & 452 & 0.92 & 0.11 & 0 & 1 & 0.96 \\
Hope (chs) & 0 - 36 & 444 & 27.33 & 5.41 & 11 & 36 & 28 \\
Effort (rc) & 1 - present, 0 - absent & 432 & 0.35 & 0.48 & 0 & 1 & 0 \\
Effort (sc) & 0 - 3 & 432 & 1.11 & 1.07 & 0 & 3 & 1 \\
Achievement (Maths) & 0 - 50 (ASER scores) & 432 & 32.29 & 11.78 & 0 & 50 & 31 \\
Achievement (English) & 0 - 50 (ASER scores) & 432 & 31.02 & 15.58 & 0 & 50 & 36 \\
ASER Score & 0 - 100 (ASER scores) & 432 & 63.25 & 24.45 & 0 & 100 & 68 \\
Father's hope & 0 - 64 (AHS) & 190 & 51.79 & 8.21 & 20 & 64 & 53 \\
Mother's hope & 0 - 64 (AHS) & 197 & 50.35 & 8.60 & 18 & 64 & 53 \\
\hline
\end{tabular}

Notes: This table displays, observations, means, standard deviations (s.d.), range and median. These statistics are presented for all the confounding factors and outcome variables. 
Table 12: A.3 Summary statistics - portraits

\begin{tabular}{ccccccc}
\hline Variable & Label & Obs & Mean & Std. dev. & Min & Max \\
& & & & & & \\
v_1 & Huge figure $(>15 \mathrm{~cm})$ & 414 & 0.031 & 0.175 & 0 & 1 \\
v_2 & Tiny figure $(<5 \mathrm{~cm})$ & 414 & 0.222 & 0.416 & 0 & 1 \\
v_3 & Monster, grotesque, genitals & 414 & 0.039 & 0.193 & 0 & 1 \\
v_4 & Shading of face or body & 414 & 0.019 & 0.138 & 0 & 1 \\
v_5 & Missing mouth & 414 & 0.068 & 0.251 & 0 & 1 \\
v_6 & Missing nose & 414 & 0.198 & 0.399 & 0 & 1 \\
v_7 & No neck & 414 & 0.258 & 0.438 & 0 & 1 \\
v_8 & No eyes & 414 & 0.056 & 0.229 & 0 & 1 \\
v_9 & Frowning, sad or crying & 414 & 0.002 & 0.049 & 0 & 1 \\
v_10 & Disproportionate body parts & 414 & 0.319 & 0.467 & 0 & 1 \\
v_11 & Poor integration of body parts & 414 & 0.034 & 0.181 & 0 & 1 \\
v_12 & Tiny head $(<1 / 6$ th body size $)$ & 414 & 0.022 & 0.146 & 0 & 1 \\
v_13 & Drawn in dark colours & 414 & 0.058 & 0.234 & 0 & 1 \\
v_14 & Drawn in single colours & 414 & 0.068 & 0.251 & 0 & 1 \\
v_15 & Drawn in light /cheery colours & 414 & 0.901 & 0.299 & 0 & 1 \\
v_16 & Bad weather & 414 & 0.007 & 0.085 & 0 & 1 \\
v_17 & Good weather & 414 & 0.338 & 0.474 & 0 & 1 \\
v_18 & Smiling & 414 & 0.901 & 0.299 & 0 & 1 \\
v_19 & Missing arms or hands & 414 & 0.152 & 0.360 & 0 & 1 \\
v_20 & Missing legs & 414 & 0.133 & 0.340 & 0 & 1 \\
v_21 & Erasure marks or scribbles & 414 & 0.510 & 0.501 & 0 & 1 \\
v_22 & Positive accessorisation & 414 & 0.705 & 0.456 & 0 & 1 \\
v_23 & Negative accessorisation & 414 & 0.007 & 0.085 & 0 & 1 \\
v_24 & Positive body language & 414 & 0.949 & 0.220 & 0 & 1 \\
v_25 & Negative body language & 414 & 0.027 & 0.161 & 0 & 1 \\
v_26 & Slanting figures & 414 & 0.135 & 0.342 & 0 & 1 \\
v_27 & Three or more figures & 414 & 0.031 & 0.175 & 0 & 1 \\
v_28 & Proper and clean alignment & 414 & 0.821 & 0.384 & 0 & 1 \\
v_29 & Long arms & 414 & 0.051 & 0.220 & 0 & 1 \\
v_30 & Legs pressed together & 414 & 0.014 & 0.120 & 0 & 1 \\
\hline & & & & & &
\end{tabular}

Notes: This table displays observations, means, standard deviations (s.d.) and range. These statistics are presented for all the codes of the portraits mentioned in section 3.3.1. 
Table 13: A.4 Empirical correlations

\begin{tabular}{|c|c|c|c|}
\hline Characteristics & Potential indication & Category & Reference \\
\hline Huge figure $(>15 \mathrm{~cm})$ & Aggressive or high self-esteem & HA & $\begin{array}{c}\text { Farokhi and Hashemi (2011), } \\
\text { Koppitz (1968) }\end{array}$ \\
\hline Tiny figure $(<5 \mathrm{~cm})$ & Shy, timid, low self-esteem & SE & $\begin{array}{l}\text { Farokhi and Hashemi (2011), } \\
\text { di Leo (1983), Koppitz (1968) }\end{array}$ \\
\hline $\begin{array}{l}\text { Monster, grotesque, } \\
\text { genitals }\end{array}$ & Aggressive & HA & $\begin{array}{c}\text { Peterson and Hardin (1997), } \\
\text { Koppitz (1968) }\end{array}$ \\
\hline Shading of face or body & Anxiety, depression, insecurity & $\mathrm{O}$ & $\begin{array}{l}\text { Farokhi and Hashemi (2011), } \\
\text { Klepsch and Logie (1982) }\end{array}$ \\
\hline Missing mouth & Anxiety, depression, insecurity & $\mathrm{O}$ & $\begin{array}{c}\text { Klepsch and Logie (1982), } \\
\text { di Leo (1983) }\end{array}$ \\
\hline Missing nose & Anxiety, depression, insecurity & $\mathrm{O}$ & $\begin{array}{l}\text { Klepsch and Logie (1982), } \\
\text { di Leo (1983), Koppitz (1968) }\end{array}$ \\
\hline No neck & Anxiety, depression, insecurity & $\mathrm{O}$ & $\begin{array}{l}\text { Klepsch and Logie (1982), di } \\
\text { Leo (1983), Koppitz (1968) }\end{array}$ \\
\hline No eyes & Anxiety, depression, insecurity & $\mathrm{O}$ & Koppitz (1968) \\
\hline Frowning, sad or crying & Anxiety, depression, insecurity & HA & Furth (2002) \\
\hline $\begin{array}{l}\text { Disproportionate body } \\
\text { parts }\end{array}$ & Shy, timid, low self-esteem & SE & $\begin{array}{l}\text { Farokhi and Hashemi (2011), } \\
\text { di Leo (1983), Koppitz (1968) }\end{array}$ \\
\hline $\begin{array}{l}\text { Poor integration of } \\
\text { body parts }\end{array}$ & Shy, timid, low self-esteem & SE & Koppitz (1968) \\
\hline $\begin{array}{l}\text { Tiny head }(<1 / 6 \text { th of } \\
\text { the body size in cms) }\end{array}$ & Low self-efficacy & SE & $\begin{array}{c}\text { Farokhi and Hashemi (2011), } \\
\text { di Leo (1983) }\end{array}$ \\
\hline Drawn in dark colours & Anxiety, depression, insecurity & $\mathrm{O}$ & Wadeson (1971) \\
\hline Drawn in single colours & Anxiety, depression, insecurity & $\mathrm{O}$ & Wadeson (1971) \\
\hline $\begin{array}{l}\text { Drawn in light } \\
\text { or cheery colours }\end{array}$ & Low anxiety, happy & HA & Wadeson (1971) \\
\hline Bad weather & Anxiety, depression, insecurity & $\mathrm{O}$ & $\begin{array}{l}\text { Farokhi and Hashemi (2011), } \\
\text { Klepsch and Logie (1982) }\end{array}$ \\
\hline Good weather & Anxiety, depression, insecurity & $\mathrm{O}$ & $\begin{array}{l}\text { Farokhi and Hashemi (2011), } \\
\text { Klepsch and Logie (1982) }\end{array}$ \\
\hline Smiling & Low anxiety, happy & HA & Furth (2002) \\
\hline Missing arms or hands & Shy, timid, low self-esteem & SE & $\begin{array}{c}\text { Furth (2002), Klepsch and } \\
\text { Logie (1982) }\end{array}$ \\
\hline Missing legs & Shy, timid, low self-esteem & SE & $\begin{array}{c}\text { Furth (2002), Koppitz (1968), } \\
\text { di Leo (1983) }\end{array}$ \\
\hline $\begin{array}{l}\text { Significant erasure marks } \\
\text { or scribble outs }\end{array}$ & Shy, timid, low self-esteem & SE & $\begin{array}{c}\text { di Leo (1983), Klepsch and } \\
\text { Logie (1982) }\end{array}$ \\
\hline Positive accessorisation & High self-efficacy, unhappy & SE & $\begin{array}{l}\text { Farokhi and Hashemi (2011), } \\
\text { Klepsch and Logie (1982) }\end{array}$ \\
\hline Negative accessorisation & Low self-efficacy, unhappy & HA & $\begin{array}{l}\text { Farokhi and Hashemi (2011), } \\
\text { Klepsch and Logie (1982) }\end{array}$ \\
\hline Positive body language & High self-efficacy, happy & HA & $\begin{array}{l}\text { Farokhi and Hashemi (2011), } \\
\text { Klepsch and Logie (1982) }\end{array}$ \\
\hline Negative body language & Low self-efficacy, happy & HA & $\begin{array}{l}\text { Farokhi and Hashemi (2011), } \\
\text { Klepsch and Logie (1982) }\end{array}$ \\
\hline Slanting figures & & SE & Koppitz (1968) \\
\hline $\begin{array}{l}\text { Three or more figures } \\
\text { spontaneously drawn }\end{array}$ & Happy, outgoing & HA & Koppitz (1968) \\
\hline $\begin{array}{c}\text { Proper and clean alignment } \\
\text { of figure }\end{array}$ & Low self-efficacy & SE & Farokhi and Hashemi (2011) \\
\hline Long arms & Aggressive or reaching out & HA & Koppitz (1968) \\
\hline Legs pressed together & Low self-efficacy & SE & Koppitz (1968) \\
\hline
\end{tabular}

Notes: The "category" column shows the characteristic that relates most closely to self-efficacy (SE), Optimism (O) or Happiness (HA). 
Table 14: A.5 Rotated factor loadings

Variable Label Factor1 Factor2 Factor3 Uniqueness

\begin{tabular}{|c|c|c|c|c|c|}
\hline V_1 & Huge figure (>15 cm) & -0.012 & -0.089 & -0.031 & 0.991 \\
\hline $\mathrm{v} \_2$ & Tiny figure $(<5 \mathrm{~cm})$ & 0.212 & 0.204 & 0.132 & 0.896 \\
\hline v_3 & Monster, grotesque, genitals & 0.102 & 0.011 & 0.084 & 0.983 \\
\hline$v_{-} 4$ & Shading of face or body & 0.174 & 0.059 & 0.078 & 0.960 \\
\hline V_5 & Missing mouth & 0.812 & 0.320 & -0.055 & 0.235 \\
\hline $\mathrm{v} \_6$ & Missing nose & 0.455 & 0.219 & 0.061 & 0.742 \\
\hline v_7 & No neck & 0.218 & 0.219 & 0.072 & 0.899 \\
\hline V_8 & No eyes & 0.766 & 0.238 & -0.063 & 0.353 \\
\hline V_9 & Frowning, sad or crying & 0.169 & -0.297 & -0.302 & 0.792 \\
\hline v_10 & Disproportionate body parts & 0.063 & 0.057 & 0.119 & 0.979 \\
\hline v_11 & Poor integration of body parts & 0.164 & 0.101 & 0.166 & 0.935 \\
\hline $\mathrm{v}_{-} 12$ & Tiny head (<1/6th body size) & -0.058 & 0.008 & -0.024 & 0.996 \\
\hline $\mathrm{v}_{-} 13$ & Drawn in dark colours & 0.342 & -0.396 & 0.447 & 0.526 \\
\hline v_14 & Drawn in single colours & 0.293 & -0.386 & 0.294 & 0.679 \\
\hline v_15 & Drawn in light / cheery colours & -0.421 & 0.543 & -0.462 & 0.315 \\
\hline v_16 & Bad weather & -0.005 & -0.033 & -0.040 & 0.997 \\
\hline v_17 & Good weather & -0.082 & 0.110 & -0.083 & 0.974 \\
\hline v_18 & Smiling & -0.780 & -0.145 & 0.126 & 0.354 \\
\hline v_19 & Missing arms or hands & 0.463 & 0.190 & 0.147 & 0.728 \\
\hline $\mathrm{v} 20$ & Missing legs & 0.349 & 0.222 & 0.139 & 0.810 \\
\hline $\mathrm{v} 21$ & Erasure marks or scribbles & 0.075 & -0.026 & 0.083 & 0.987 \\
\hline $\mathrm{v} 22$ & Positive accessorisation & -0.200 & 0.142 & 0.084 & 0.933 \\
\hline $\mathrm{v} 23$ & Negative accessorisation & 0.241 & -0.269 & -0.392 & 0.717 \\
\hline $\mathrm{v} 24$ & Positive body language & -0.674 & 0.229 & 0.281 & 0.415 \\
\hline $\mathrm{v} 25$ & Negative body language & 0.470 & -0.400 & -0.424 & 0.439 \\
\hline $\mathrm{v} 26$ & Slanting figures & 0.048 & -0.039 & 0.049 & 0.994 \\
\hline $\mathrm{v} 27$ & Three or more figures & 0.086 & 0.124 & 0.008 & 0.977 \\
\hline $\mathrm{v} 28$ & Proper and clean alignment & -0.259 & -0.073 & -0.176 & 0.897 \\
\hline $\mathrm{v} 29$ & Long arms & -0.028 & 0.015 & 0.060 & 0.996 \\
\hline $\mathrm{v} 30$ & Legs pressed together & 0.042 & 0.056 & 0.041 & 0.994 \\
\hline
\end{tabular}

Notes: This table displays the orthogonally rotated factor loadings for the pre-coded drawing characteristics, discussed in section 3.3.1. Loadings greater than 0.33 (in magnitude) are retained for factor composition to have meaningfully inferable factors. These are presented in the next table. The last column on 'Uniqueness', reports the proportion of the common variance that is not related to any of the other factors. 
Table 15: A.6: Factor composition

Panel (a): Self-efficacy or Optimism

\begin{tabular}{|c|c|c|c|c|c|}
\hline Variable & Variable label & $\begin{array}{c}\text { Factor1 } \\
\text { (SE/Optimism) }\end{array}$ & Factor2 Factor3 & Uniqueness & $\begin{array}{l}\text { Associated } \\
\text { characteristic }\end{array}$ \\
\hline $\mathrm{v} \_1_{1}$ & Huge figure $(>15 \mathrm{~cm})$ & & & 0.991 & \\
\hline $\mathrm{v} \_2$ & Tiny figure $(<5 \mathrm{~cm})$ & & & 0.896 & \\
\hline v_3 & Monster, grotesque, genitals & & & 0.983 & \\
\hline V_4 & Shading of face or body & & & 0.960 & \\
\hline v_5 & Missing mouth & 0.873 & & 0.235 & Optimism \\
\hline v_6 & Missing nose & 0.501 & & 0.742 & Optimism \\
\hline v_7 & No neck & & & 0.899 & \\
\hline $\mathrm{v} \_8$ & No eyes & 0.796 & & 0.353 & Optimism \\
\hline v_9 & Frowning, sad or crying & & -0.451 & 0.792 & Happiness \\
\hline V_10 & Disproportionate body parts & & & 0.979 & \\
\hline V_11 & Poor integration of body parts & & & 0.935 & \\
\hline v_12 & Tiny head ( $<1 / 6$ th body size) & & & 0.996 & \\
\hline v_13 & Drawn in dark colours & & 0.679 & 0.526 & Optimism \\
\hline V_14 & Drawn in single colours & & 0.551 & 0.679 & Optimism \\
\hline V_15 & Drawn in light / cheery colours & & -0.812 & 0.315 & Happiness \\
\hline v_16 & Bad weather & & & 0.997 & \\
\hline v_17 & Good weather & & & 0.974 & \\
\hline v_18 & Smiling & -0.773 & & 0.354 & Happiness \\
\hline v_19 & Missing arms or hands & 0.492 & & 0.728 & Self-efficacy \\
\hline v_20 & Missing legs & 0.402 & & 0.810 & Self-efficacy \\
\hline $\mathrm{v} \_21$ & Erasure marks or scribbles & & & 0.987 & \\
\hline $\mathrm{v} \_22$ & Positive accessorisation & & & 0.933 & \\
\hline $\mathrm{v} \_23$ & Negative accessorisation & & -0.52 & 0.717 & SE/HA \\
\hline v_24 & Positive body language & -0.525 & 0.52 & 0.415 & Happiness \\
\hline $\mathrm{v} \_25$ & Negative body language & & -0.68 & 0.439 & Happiness \\
\hline v_26 & Slanting figures & & & 0.994 & \\
\hline $\mathrm{v} \_27$ & Three or more figures & & & 0.977 & \\
\hline $\mathrm{v} \_28$ & Proper and clean alignment & & & 0.897 & \\
\hline v_29 & Long arms & & & 0.996 & \\
\hline v_30 & Legs pressed together & & & 0.994 & \\
\hline
\end{tabular}

Notes: Retained loadings from table A.5 and the empirical correlations of these variables are presented in column (3) and (7), respectively. The last column on 'Uniqueness', is the same as in table A.5. 
Table 16: A.6: Factor composition (table continued)

Panel (b): Happiness

\begin{tabular}{|c|c|c|c|c|c|c|}
\hline Variable & Variable label & Factor1 & Factor2 & $\begin{array}{c}\text { Factor3 } \\
\text { (Happiness) }\end{array}$ & Uniqueness & $\begin{array}{c}\text { Associated } \\
\text { characteristic }\end{array}$ \\
\hline v_1 & Huge figure $(>15 \mathrm{~cm})$ & & & & 0.991 & \\
\hline $\mathrm{v} \_2$ & Tiny figure $(<5 \mathrm{~cm})$ & & & & 0.896 & \\
\hline v_3 & Monster, grotesque, genitals & & & & 0.983 & \\
\hline $\mathrm{v} \_4$ & Shading of face or body & & & & 0.960 & \\
\hline V_5 & Missing mouth & 0.873 & & & 0.235 & Optimism \\
\hline $\mathrm{v} \_6$ & Missing nose & 0.501 & & & 0.742 & Optimism \\
\hline v_7 & No neck & & & & 0.899 & \\
\hline $\mathrm{v} \_8$ & No eyes & 0.796 & & & 0.353 & Optimism \\
\hline V_9 & Frowning, sad or crying & & & -0.451 & 0.792 & Happiness \\
\hline v_10 & $\overline{\text { Disproportionate body parts }}$ & & & & 0.979 & \\
\hline v_11 & Poor integration of body parts & & & & 0.935 & \\
\hline v_12 & Tiny head ( $<1 / 6$ th body size) & & & & 0.996 & \\
\hline v_13 & Drawn in dark colours & & 0.679 & & 0.526 & Optimism \\
\hline v_14 & Drawn in single colours & & 0.551 & & 0.679 & Optimism \\
\hline v_15 & Drawn in light / cheery colours & & -0.812 & & 0.315 & Happiness \\
\hline v_16 & Bad weather & & & & 0.997 & \\
\hline v_17 & Good weather & & & & 0.974 & \\
\hline v_18 & Smiling & -0.773 & & & 0.354 & Happiness \\
\hline v_19 & Missing arms or hands & 0.492 & & & 0.728 & Self-efficacy \\
\hline v_20 & Missing legs & 0.402 & & & 0.810 & Self-efficacy \\
\hline v_21 & Erasure marks or scribbles & & & & 0.987 & \\
\hline $\mathrm{v} \_22$ & Positive accessorisation & & & & 0.933 & \\
\hline v_23 & Negative accessorisation & & & -0.52 & 0.717 & $\mathrm{SE} / \mathrm{HA}$ \\
\hline v_24 & Positive body language & -0.525 & & 0.52 & 0.415 & Happiness \\
\hline $\mathrm{v} \_25$ & Negative body language & & & -0.68 & 0.439 & Happiness \\
\hline $\mathrm{v} \_26$ & Slanting figures & & & & 0.994 & \\
\hline $\mathrm{v} \_27$ & Three or more figures & & & & 0.977 & \\
\hline $\mathrm{v}-28$ & Proper and clean alignment & & & & 0.897 & \\
\hline $\mathrm{v} \_29$ & Long arms & & & & 0.996 & \\
\hline v_30 & Legs pressed together & & & & 0.994 & \\
\hline
\end{tabular}

Notes: Retained loadings from table A.5 and the empirical correlations of these variables are presented in column (5) and (7), respectively. The last column on 'Uniqueness', is the same as in table A.5. 
Table 17: A.7 Baseline relationships

\begin{tabular}{cccccc}
\hline Variable & $\begin{array}{c}(1) \\
\text { Math }\end{array}$ & $\begin{array}{c}(2) \\
\text { English }\end{array}$ & $\begin{array}{c}(3) \\
\text { Hope }\end{array}$ & $\begin{array}{c}(4) \\
\text { Effort (sc) }\end{array}$ & $\begin{array}{c}(5) \\
\text { Effort (rc) }\end{array}$ \\
Hope & & & & & \\
& $0.427^{* * *}$ & 0.154 & & 0.007 & 0.002 \\
Substitution class & $(0.088)$ & $(0.124)$ & & $(0.009)$ & $(0.004)$ \\
& 0.593 & $1.665^{* *}$ & 0.185 & & 0.024 \\
Remedial class & $(0.443)$ & $(0.618)$ & $(0.245)$ & & $(0.022)$ \\
& $2.716^{* * *}$ & 2.084 & 2.80 & 0.119 & \\
Past perform. & $(0.989)$ & $(1.377)$ & $(0.547)$ & $(0.110)$ & \\
records & $0.384^{* * *}$ & $0.452^{* * *}$ & -0.002 & -0.001 & -0.001 \\
Age & $(0.031)$ & $(0.044)$ & $(0.020)$ & $(0.004)$ & $(0.001)$ \\
& $-2.098^{* *}$ & $-2.027^{*}$ & $0.876^{*}$ & -0.141 & -0.003 \\
Gender & $(0.645)$ & $(0.898)$ & $(0.355)$ & $(0.072)$ & $(0.032)$ \\
& $2.306^{*}$ & -1.651 & 0.400 & $-0.222^{*}$ & 0.014 \\
Private tuition & $(0.962)$ & $(1.340)$ & $(0.528)$ & $(0.106)$ & $(0.047)$ \\
& $2.135^{*}$ & 0.858 & -0.166 & -0.111 & 0.003 \\
Religion & $(0.965)$ & $(1.344)$ & $(0.531)$ & $(0.107)$ & $(0.048)$ \\
& -0.495 & -0.179 & 1.210 & -0.053 & 0.041 \\
Hh size & $(1.437)$ & $(2.002)$ & $(0.786)$ & $(0.159)$ & $(0.071)$ \\
& 0.007 & $-0.439^{* *}$ & 0.018 & -0.006 & $-0.011^{*}$ \\
Hours studied & $(0.105)$ & $(0.146)$ & $(0.057)$ & $(0.011)$ & $(0.005)$ \\
at home/week & 0.023 & 0.114 & 0.037 & -0.008 & -0.001 \\
Achievement & $(0.106)$ & $(0.148)$ & $(0.058)$ & $(0.011)$ & $(0.005)$ \\
(Total) & & & $0.042^{* *}$ & $0.006^{*}$ & $0.003^{*}$ \\
Constant & & & $(0.013)$ & $(0.002)$ & $(0.001)$ \\
& & & & & \\
\hline$N$ & $(6.331$ & 14.23 & $13.89^{* * *}$ & $2.229^{* *}$ & 0.189 \\
& & $(9.343)$ & $(3.630)$ & $(0.736)$ & $(0.334)$ \\
\hline & 423 & 423 & 423 & 423 & 423 \\
\hline
\end{tabular}

Notes: The table displays the baseline associations between the confounding factors and the main outcome variables in columns (1)-(5). Standard errors are in parentheses with ${ }^{* * *} \mathrm{p}<0.01{ }^{* *} \mathrm{p}<0.05$ and ${ }^{*} \mathrm{p}<0.1$. 
Table 18: A.8 Attrition balance test

\begin{tabular}{ccccccc}
\hline \multirow{2}{*}{ Attrition rate } & \multicolumn{2}{c}{ Control } & \multicolumn{2}{c}{ Treatment } & Difference & \multirow{2}{*}{ p-value } \\
& mean & sd & mean & sd & $(\mathrm{C}-\mathrm{T})$ & \\
\hline $\mathrm{CHS}$ & 0.0176 & 0 & 0.017 & 0 & 0 & $\cdot$ \\
$\mathrm{N}$ & 222 & & 222 & & \\
& & & & & & \\
Drawings & 0.084 & 0 & 0.084 & 0 & 0 &. \\
$\mathrm{~N}$ & 207 & 207 & & \\
Effort (sc) & 0.044 & 0 & 0.044 & 0 & 0 &. \\
$\mathrm{~N}$ & 216 & 216 & & \\
\hline
\end{tabular}

Notes: Difference in mean attrition between treatment and placebo (here, control) over hope (chs), drawings and substitution class (sc). Attrition for learning outcomes is same as effort (substitution class). 


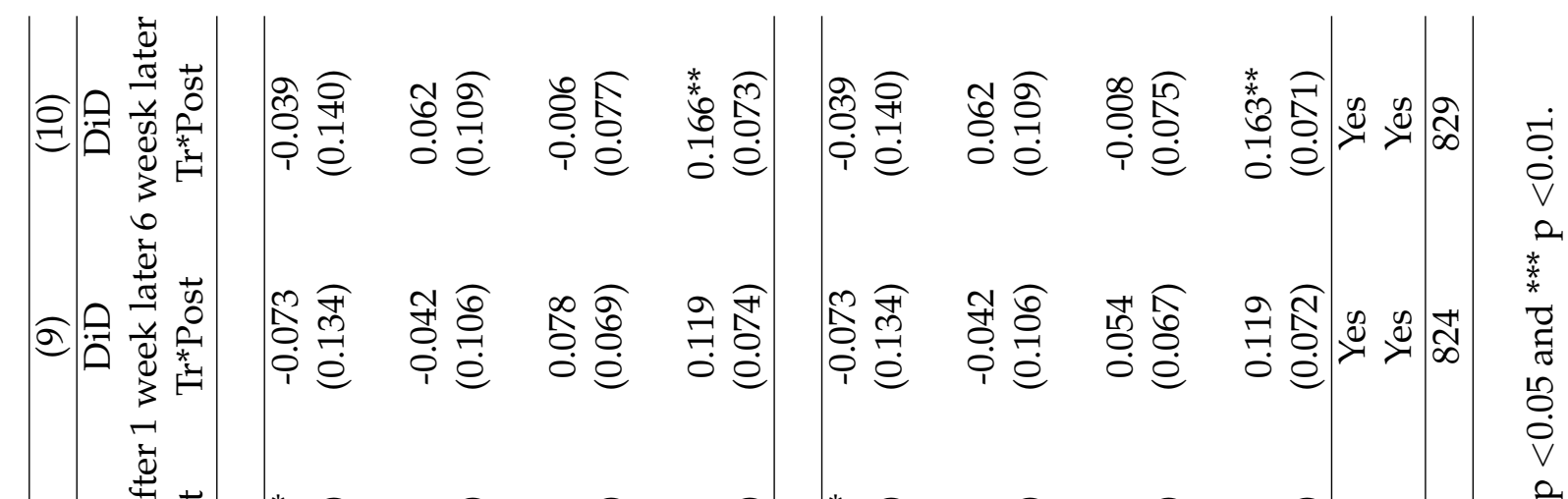

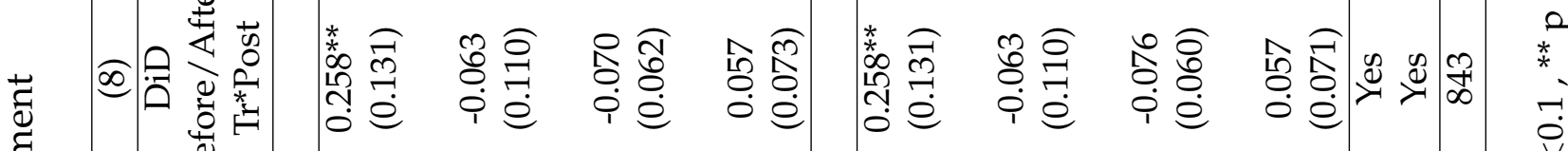
E

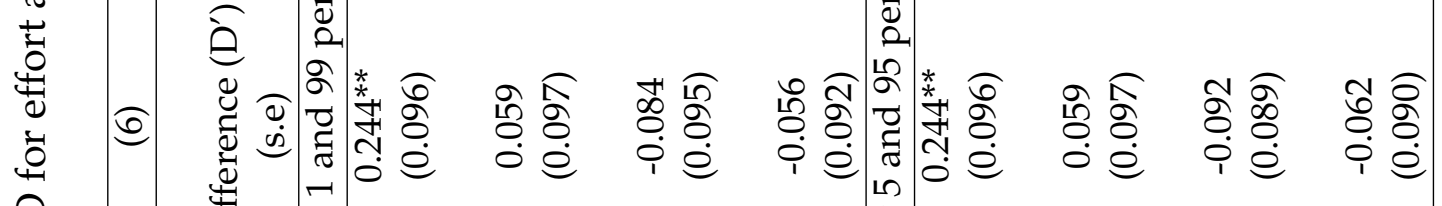

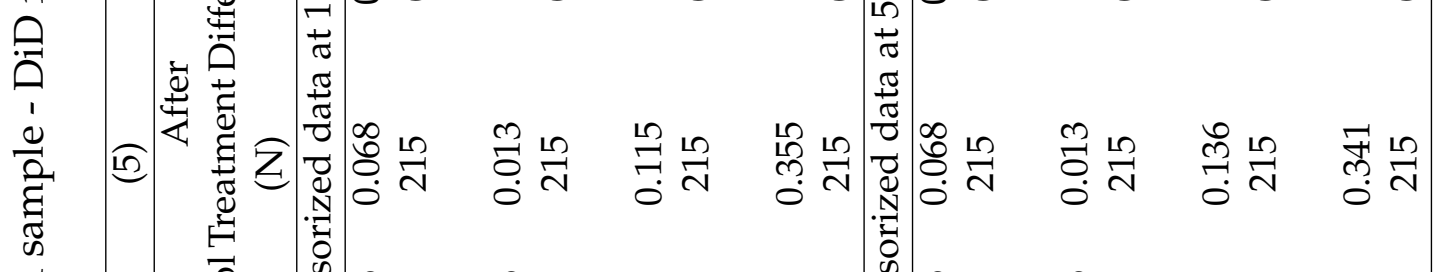
.

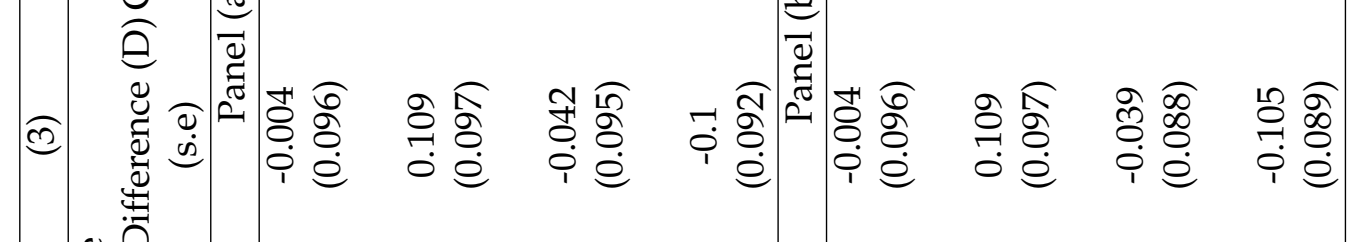
을

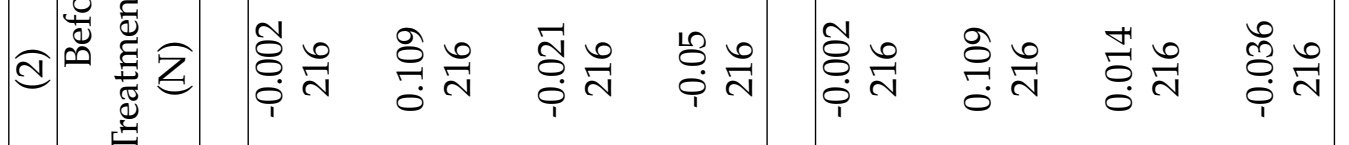

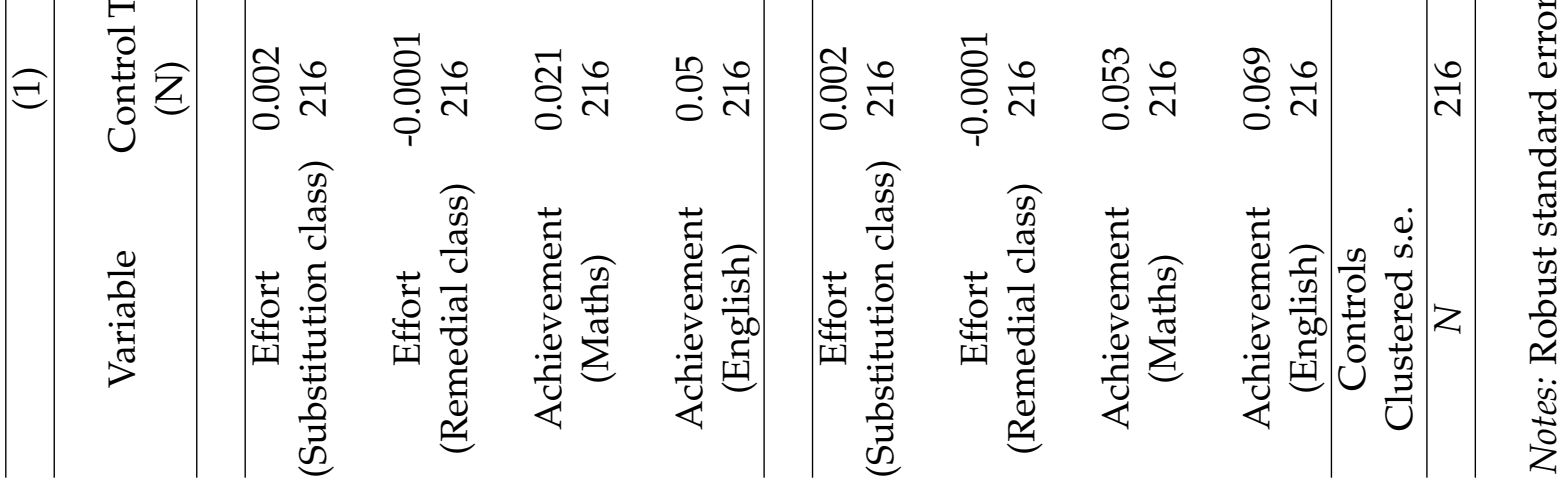




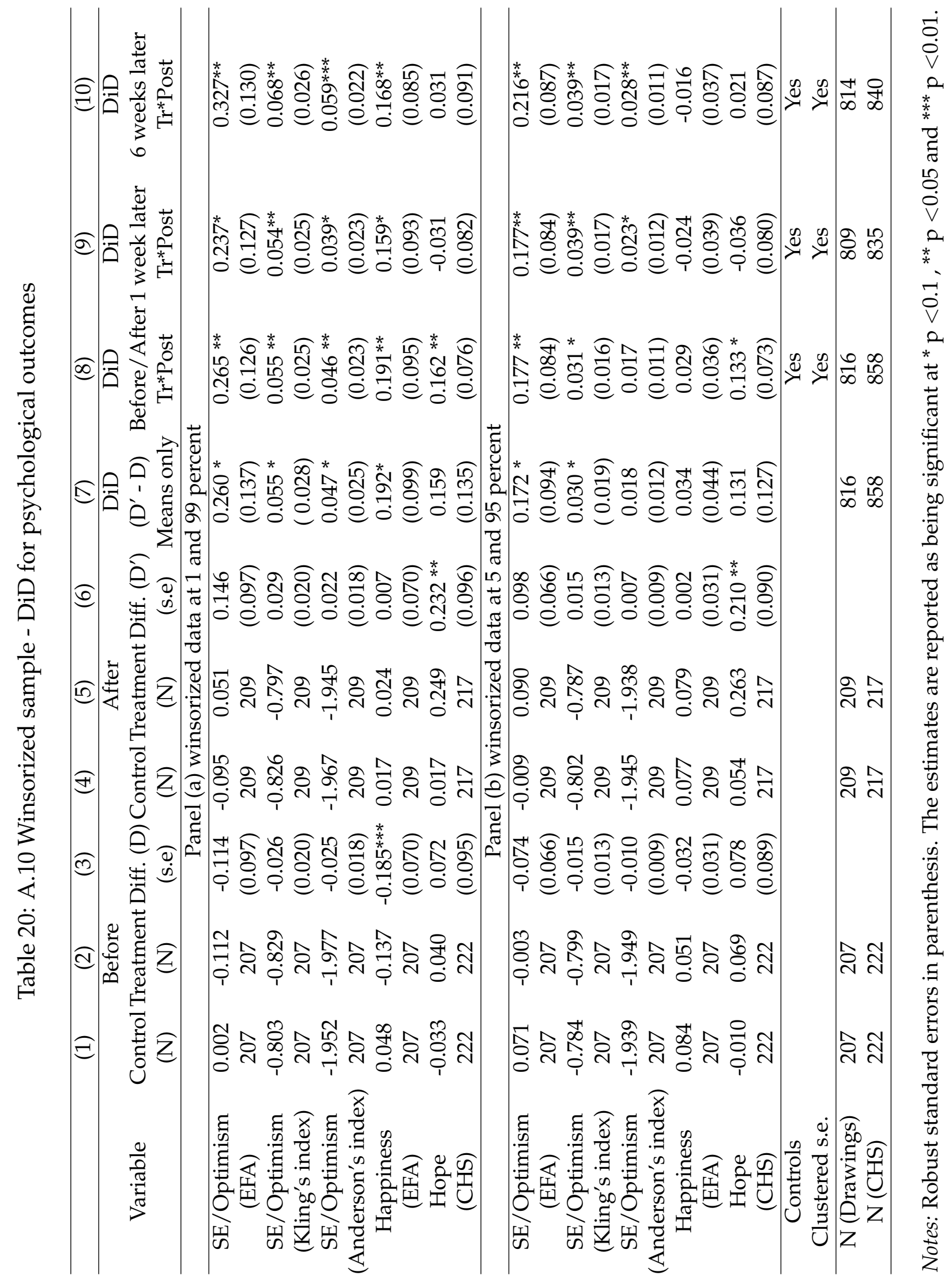


Table 21: A.11 Treatment effect on student attendance

\begin{tabular}{lcccccc}
\hline & $(1)$ & $(2)$ & $(3)$ & $(4)$ & $(5)$ & $(6)$ \\
\hline September & -0.005 & & & & & \\
& $(0.010)$ & & & & & \\
October & & 0.011 & & & & \\
& & $(0.010)$ & & & & \\
November & & & -0.008 & & & \\
& & & $(0.012)$ & & & \\
December & & & & -0.004 & & \\
& & & & $(0.011)$ & & \\
January & & & & & $0.0244^{* *}$ & \\
& & & & & $(0.011)$ & \\
Overall & & & & & & $0.022 * * *$ \\
& & & & & & $(0.005)$ \\
& & & & & & \\
Controls & & $\checkmark$ & $\checkmark$ & $\checkmark$ & $\checkmark$ & $\checkmark$ \\
Adjusted r-square & 0.190 & 0.301 & 0.255 & 0.263 & 0.267 & 0.222 \\
$N$ & 452 & 452 & 452 & 452 & 452 & 2260 \\
\hline
\end{tabular}

Notes: The intervention was conducted in the last week of August. I compare the effect of treatment on each month's attendance (in fraction) after the intervention using Ancova. The last row presents the overall treatment effect from the pooled sample. Standard errors are in parentheses with ${ }^{* * *} \mathrm{p}<0.01,{ }^{* *} \mathrm{p}<0.05$ and ${ }^{*} \mathrm{p}<0.1$. 
Table 22: A.12 DiD for student attendance

\begin{tabular}{|c|c|c|c|c|c|c|c|c|}
\hline & (1) & (2) & (3) & (4) & (5) & (6) & (7) & (8) \\
\hline & \multicolumn{2}{|c|}{ Before } & Diff & \multicolumn{2}{|c|}{ After } & Diff & Treatment & Treatment \\
\hline & $\mathrm{C}$ & $\mathrm{T}$ & $(\mathrm{T}-\mathrm{C})$ & $\mathrm{C}$ & $\mathrm{T}$ & $(\mathrm{T}-\mathrm{C})$ & effect & effect \\
\hline $\begin{array}{c}\text { Attendance } \\
\text { (fraction) }\end{array}$ & 0.899 & 0.893 & $\begin{array}{l}-0.006 \\
(0.012)\end{array}$ & 0.841 & 0.861 & $\begin{array}{l}0.020^{*} \\
(0.012)\end{array}$ & $\begin{array}{l}0.026 \\
(0.017)\end{array}$ & $\begin{array}{l}0.025^{* *} \\
(0.012)\end{array}$ \\
\hline Controls & & & & & & & & $\checkmark$ \\
\hline $\begin{array}{c}\text { Clustered se } \\
\qquad N\end{array}$ & 226 & 226 & 452 & 226 & 226 & 452 & 452 & $\begin{array}{l}\checkmark \\
904\end{array}$ \\
\hline
\end{tabular}

Notes: I compare the attendance fractions before (August) and after 5-months (January) the intervention. Column (1)-(6) display simple mean comparisons. Column (8) reports the DiD estimates. Standard errors are in parantheses with ${ }^{* * *}$ $\mathrm{p}<0.01,{ }^{* *} \mathrm{p}<0.05$, and ${ }^{*} \mathrm{p}<0.1$.

Table 23: A.13 FWER test

\begin{tabular}{ccccc}
\hline Variable & $\begin{array}{c}(1) \\
\text { Effect }\end{array}$ & $\begin{array}{c}(2) \\
\text { Naive p-value }\end{array}$ & $\begin{array}{c}(3) \\
\text { FWER p-value }\end{array}$ & $\begin{array}{c}(4) \\
\mathrm{N}\end{array}$ \\
\hline $\begin{array}{c}\text { Self-esteem/Optimism } \\
\text { (Anderson's Index) }\end{array}$ & $\begin{array}{c}0.048 \\
(0.023)\end{array}$ & 0.037 & 0.064 & 832 \\
$\begin{array}{c}\text { Self-esteem/Optimism } \\
\text { (Kling's index) }\end{array}$ & $\begin{array}{c}0.055 \\
(0.025)\end{array}$ & 0.028 & 0.064 & 832 \\
$\begin{array}{c}\text { Self-esteem/Optimism } \\
\text { (EFA) }\end{array}$ & $\begin{array}{c}0.27 \\
(0.125)\end{array}$ & 0.032 & 0.064 & 832 \\
\hline
\end{tabular}

Notes: I reproduce the family wise error rate adjusted p-values based on Anderson (2008). Column (1) reports the treatment effect. Column (2) and (3) report the naive and FWER-adjusted p-values, respectively. See section 5.4 for details. Clustered standard errors are present in parenthesis. 


\subsection{Figures}

Figure A.1: Point estimates by treatment status over time

(a) Hope

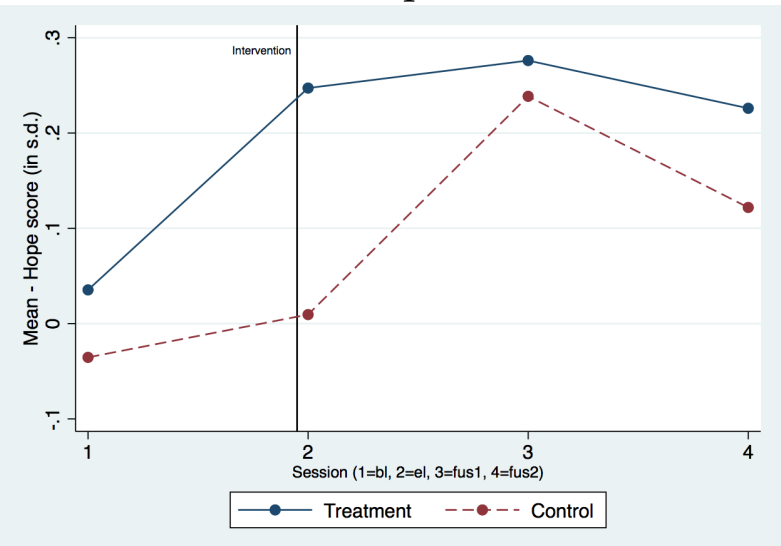

(c) Remedial Class

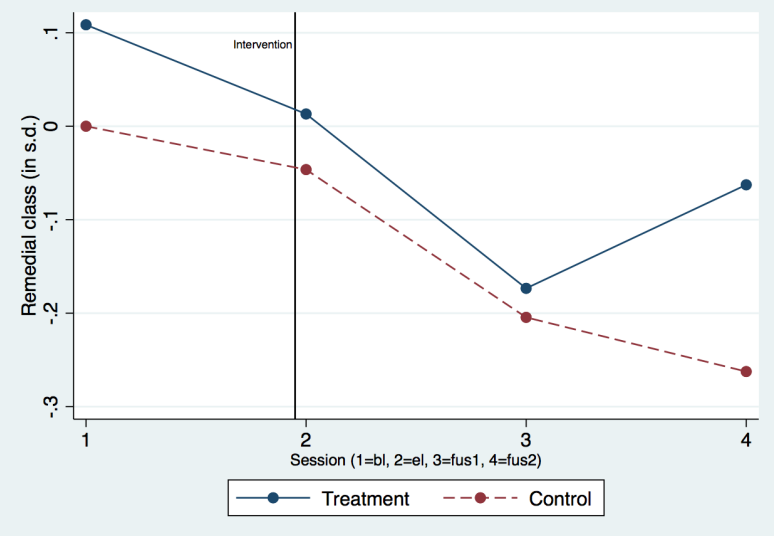

(e) Maths

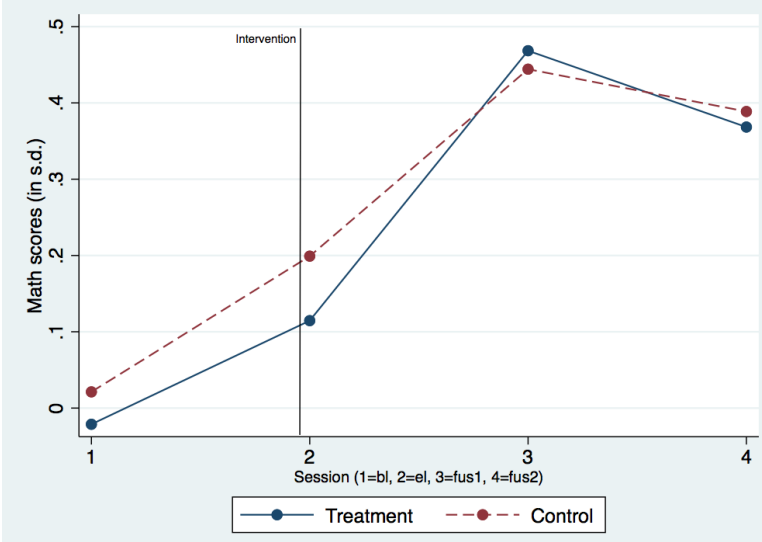

(b) SE/Optimism

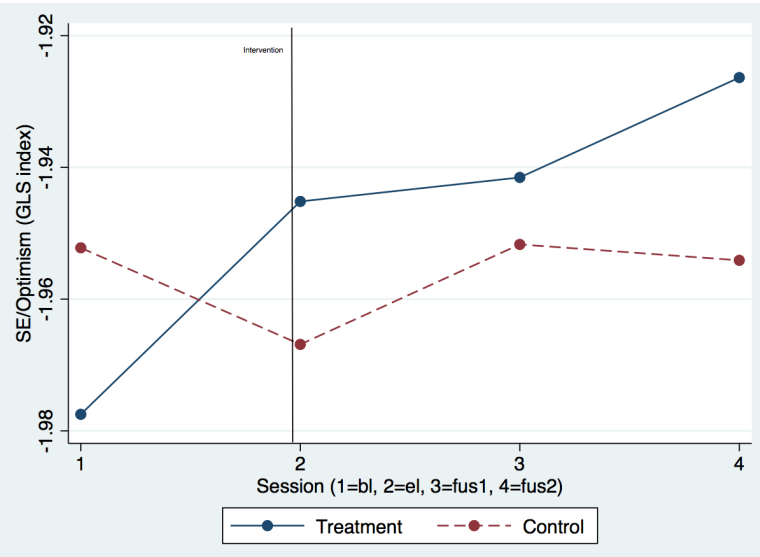

(d) Attendance

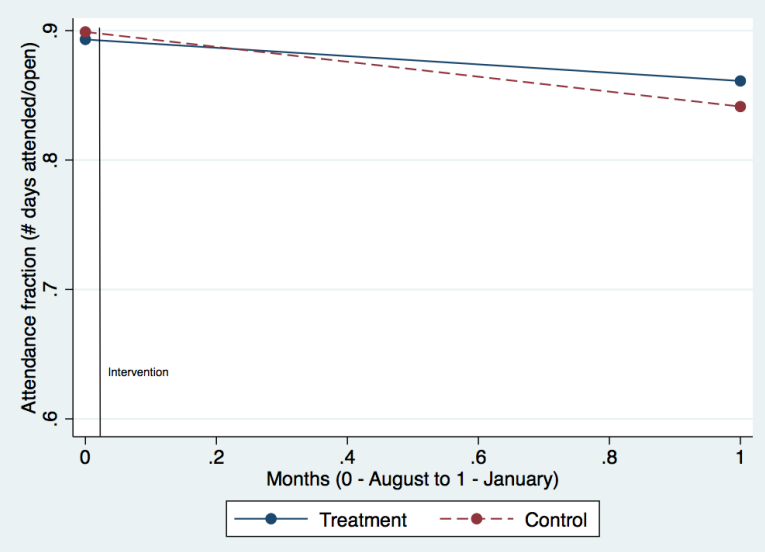

(f) English

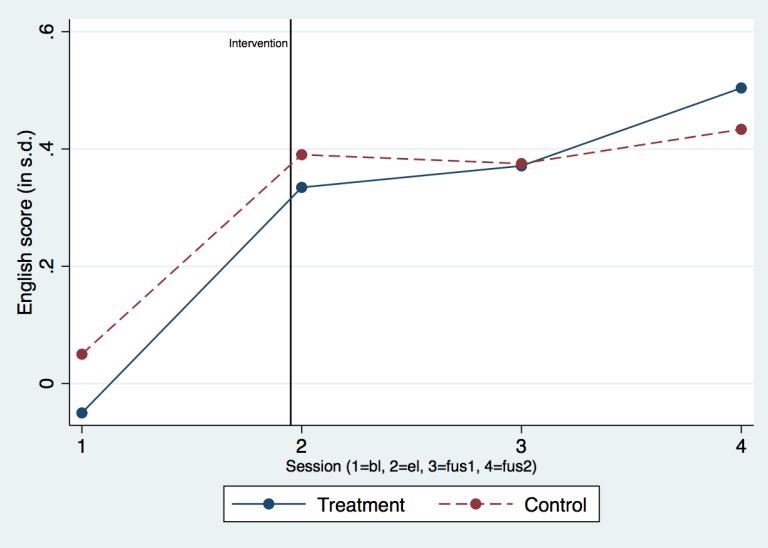

Notes: Panel (a)-(f) display the point estimates for the outcome variables by treatment and placebo (control - in the figures) over the different rounds of data collection. 
Figure A.2: A sample of self-portraits

Panel A

(a) Self-efficacy/Optimism - 5 percentile

(b) SE/Optimism - 95 percentile
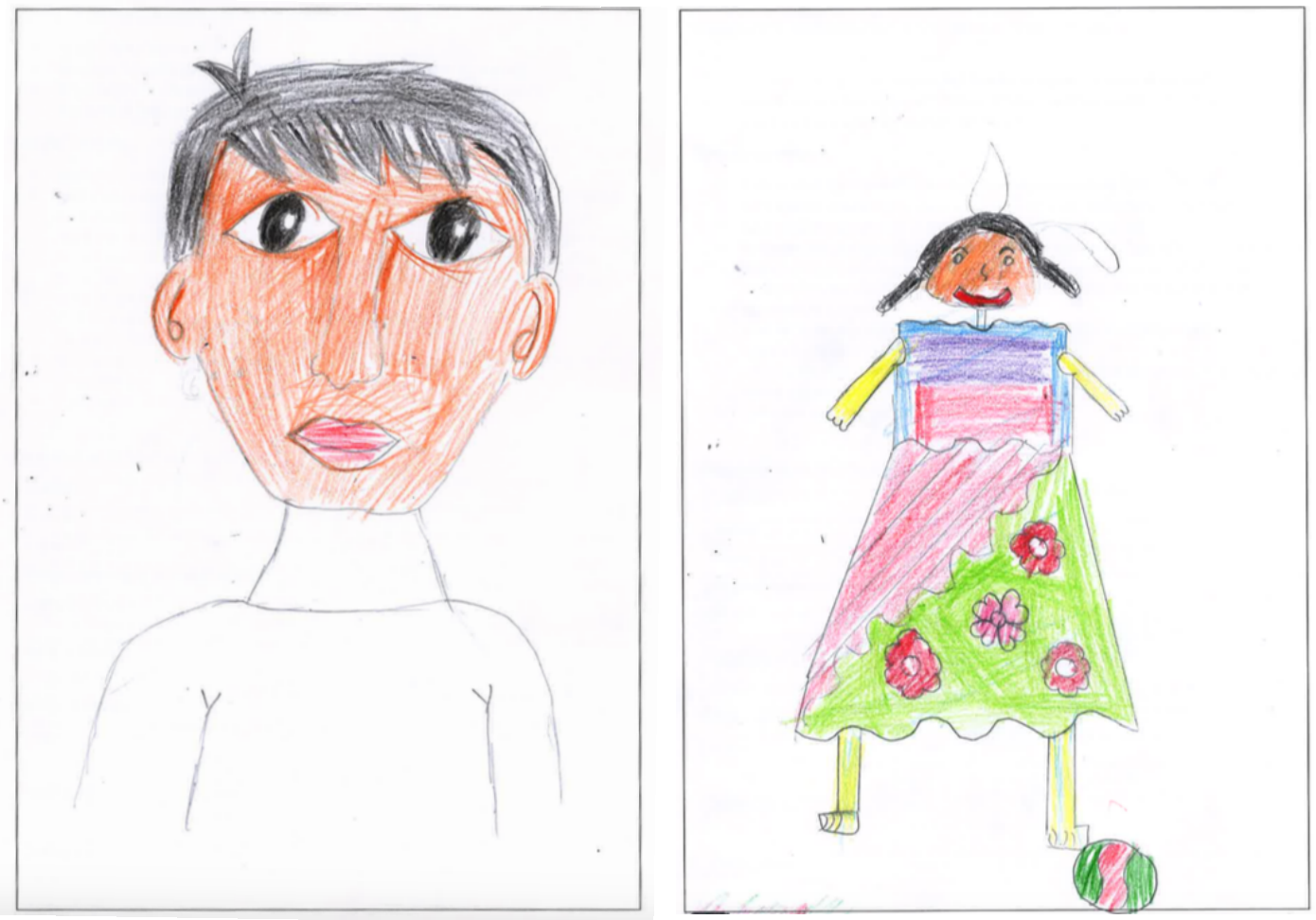

Panel B

(c) Happiness - 5 percentile

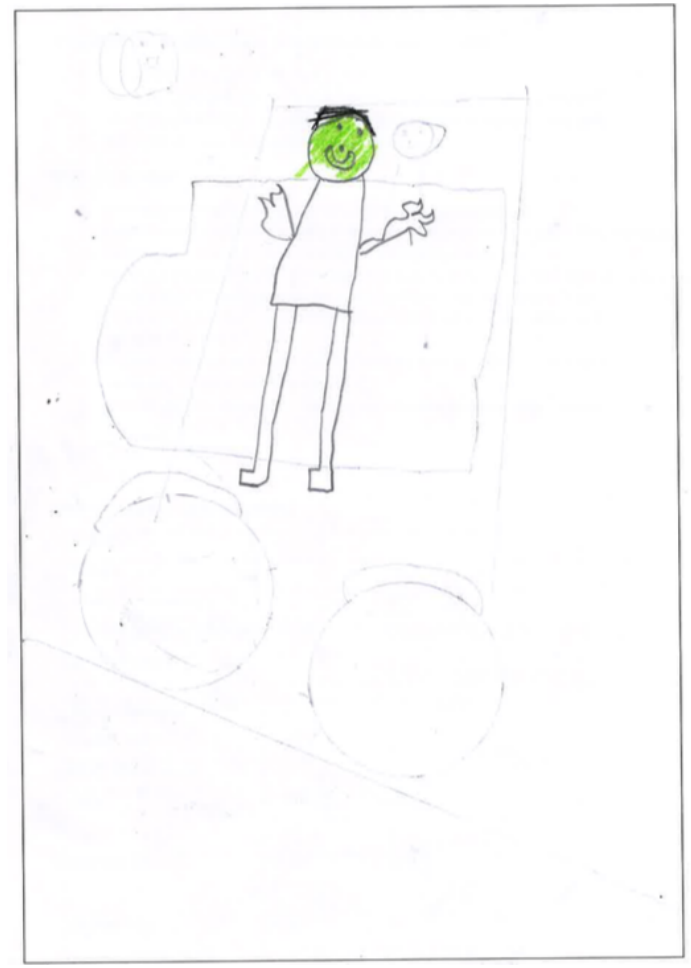

(d) Happiness - 95 percentile

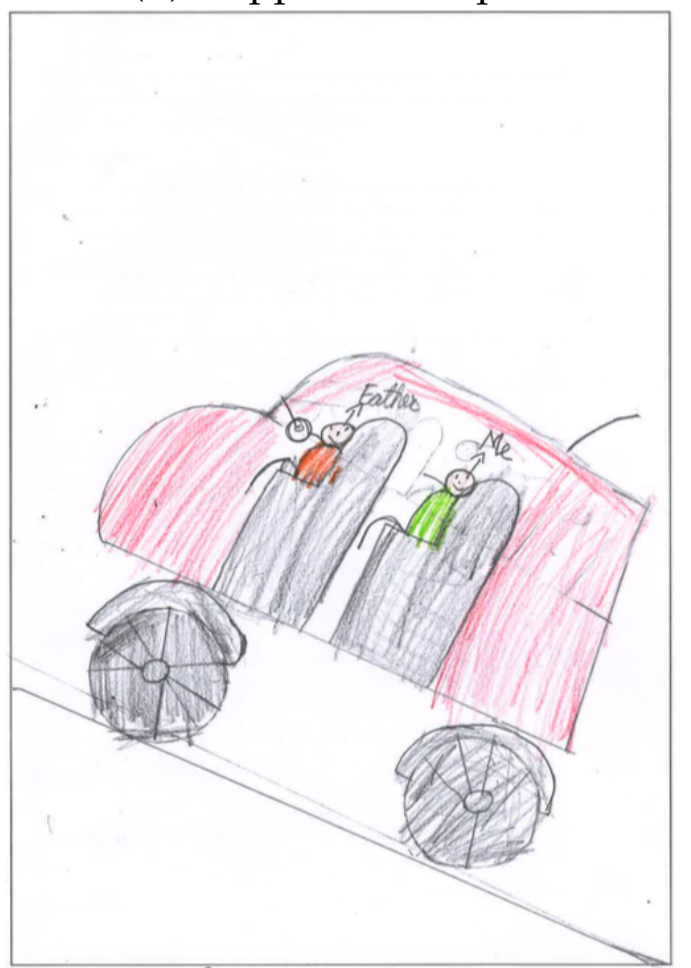


Figure A.3: Children's Hope Scale (CHS)

\section{Information about yourself}

1 I think I am doing pretty well.

$\mathrm{O}$

$\mathrm{O}$

$\mathrm{O}$

$\mathrm{O}$

$\mathrm{O}$

$\mathrm{O}$

None of A little of Some of A lot of Most of All of

the time the time the time the time the time the time

2

I can think of many ways to get the things in life that are most important to me.

$\mathrm{O}$

$\mathrm{O}$

$\mathrm{O}$

$\mathrm{O}$

$\mathrm{O}$

$\mathrm{O}$

None of A little of Some of A lot of Most of All of the time the time the time the time the time the time

3 I am doing just as well as other kids my age.
$\mathrm{O}$
$\mathrm{O}$
$\mathrm{O}$
$\mathrm{O}$
$\mathrm{O}$
$\mathrm{O}$

None of A little of Some of A lot of Most of All of the time the time the time the time the time the time

4

When I have a problem, I can come up with lots of ways to solve it.

$\mathrm{O}$

$\mathrm{O}$

$\mathrm{O}$

Some of

the time the time the time
$\mathrm{O}$

A lot of

the time
$\mathrm{O}$

Most of

the time
$\mathrm{O}$

All of

the time

I think the things I have done in the past will help me in the future.

$$
\mathrm{O}
$$

$\mathrm{O}$

$\mathrm{O}$

$\mathrm{O}$

$\mathrm{O}$

$\mathrm{O}$

None of A little of Some of A lot of Most of All of the time the time the time the time the time the time

Even when others want to quit, I know that I can find ways to solve the problem.

$$
\mathrm{O}
$$

$\mathrm{O}$

$\mathrm{O}$

$\mathrm{O}$

None of A little of Some of A lot of Most of All of

$\mathrm{O}$

$\mathrm{O}$ the time the time the time the time the time the time

Notes: CHS was administered to students with 10 additional priming free statements. The scale was renamed as 'Information about yourself', and administered with the following instruction: "Read each sentence carefully. For each sentence, please think about how you are in most situations. Place a check inside the circle that describes you the best. For example, place a check $(\checkmark)$ in the circle (O) above "None of the time," if this describes you. Alternatively, if you are this way "All of the time," check this circle. Please respond to every statement by putting a check in one of the circles. There are no right or wrong answers." 